\title{
Comparative Gene Expression Analysis Reveals Mechanism of Pinus contorta Response to the Fungal Pathogen Dothistroma septosporum
}

\author{
Mengmeng Lu, ${ }^{1+}$ Nicolas Feau, ${ }^{2}$ Dragana Obreht Vidakovic, ${ }^{2}$ Nicholas Ukrainetz, ${ }^{3}$ Barbara Wong, ${ }^{4}$ \\ Sally N. Aitken, ${ }^{2}$ Richard C. Hamelin, ${ }^{2,4}$ and Sam Yeaman ${ }^{1}$ \\ ${ }^{1}$ Department of Biological Sciences, University of Calgary, 507 Campus Drive NW, Calgary, Canada \\ ${ }^{2}$ Department of Forest and Conservation Sciences, University of British Columbia, 3041-2424 Main Mall, Vancouver, Canada \\ ${ }^{3}$ Forest Improvement and Research Management Branch, Ministry of Forests, Lands and Natural Resource Operations \& Rural \\ Development, 18793-32nd Ave., Surrey, Canada \\ ${ }^{4}$ Institut de Biologie Intégrative et des Systèmes, Université Laval, Pavillon Charles-Eugène-Marchand 1030, avenue de la \\ Médecine, Québec, Canada
}

Accepted 30 November 2020.

\begin{abstract}
Many conifers have distributions that span wide ranges in both biotic and abiotic conditions, but the basis of response to biotic stress has received much less attention than response to abiotic stress. In this study, we investigated the gene expression response of lodgepole pine (Pinus contorta) to attack by the fungal pathogen Dothistroma septosporum, which causes Dothistroma needle blight, a disease that has caused severe climate-related outbreaks in northwestern British Columbia. We inoculated tolerant and susceptible pines with two $D$. septosporum isolates and analyzed the differentially expressed genes (DEGs), differential exon usage, and coexpressed gene modules using RNA-sequencing data. We found a rapid and strong transcriptomic response in tolerant lodgepole pine samples inoculated with one $D$. septosporum isolate, and a late and weak response in susceptible samples inoculated with another isolate. We mapped 43 of the DEG- or gene module-identified genes to the reference plant-pathogen interaction pathway deposited in the Kyoto Encyclopedia of Genes and Genomes database. These genes are present in PAMP-triggered and effectortriggered immunity pathways. Genes comprising pathways and gene modules had signatures of strong selective constraint, while the highly expressed genes in tolerant samples appear to
\end{abstract}

The raw reads obtained from RNA-sequencing have been deposited in the National Center for Biotechnology Information Sequence Read Archive (accession number BioProject ID PRJNA602898). The lodgepole pine reference transcriptome, the gene annotation files, and the identified gene lists have been deposited in Dryad under doi 10.5061/dryad.1vhhmgqps.

${ }^{\dagger}$ Corresponding author: M. Lu; mengmeng.lu@ucalgary.ca

Funding: This work was supported by the CoAdapTree Project (241REF), with funding from Genome Canada, Genome BC, Genome Alberta, Genome Québec, the BC Ministry of Forests, Lands, Natural Resource Operations and Rural Development, as well as many other sponsors and seed contributors. S. Yeaman is also funded by the Natural Sciences and Engineering Research Council of Canada (NSERC) and Alberta Innovates.

*The $e$-Xtra logo stands for "electronic extra" and indicates there are supplementary materials published online.

The author(s) declare no conflict of interest.

(c) (1) () $\odot$ Copyright () 2021 The Author(s). This is an open access article distributed under the CC BY-NC-ND 4.0 International license. have been favored by selection to counterattack the pathogen. We identified candidate resistance genes that may respond to $D$. septosporum effectors. Taken together, our results show that gene expression response to $D$. septosporum infection in lodgepole pine varies both among tree genotypes and pathogen strains and involves both known candidate genes and a number of genes with previously unknown functions.

Keywords: $d_{\mathrm{N}} / d_{\mathrm{S}}$, evolutionary rate, gymnosperm, plant defense, $R$ genes, transcriptome

Pathogens can pose a serious challenge to plant survival and fecundity, yet the basis of plant response to pathogens tends to be less well studied than response to abiotic stress, at least in nonmodel species. Most of our knowledge about plant defense, such as plant-pathogen signaling pathways and coevolutionary dynamics, come from studies in just a few angiosperm species. Much less is known about the defense mechanism in gymnosperms, the nonflowering lineage of seed plant. Long generation time and a large genome complicate endeavors to understand the defense mechanism of coniferous species (De La Torre et al. 2014). However, the availability of genomic resources and knowledge gained from angiosperms can help to infer how gymnosperms mount their defense response (de Vries et al. 2018).

Lodgepole pine (Pinus contorta), an evergreen conifer species, inhabits wide ranges of the montane and interior plateau regions of western Canada and the United States (Fryer 2018). In recent decades, an outbreak of Dothistroma needle blight (DNB) has caused defoliation and mortality on lodgepole pine in northwestern British Columbia, raising concerns about growth and yield (Welsh et al. 2009; Woods 2003). DNB or red band needle blight, caused by the endemic fungal pathogen Dothistroma septosporum, mainly infects needles of pines, causing needle necrosis and tree defoliation that lead to growth reduction and, in the most severe cases, branch and tree mortality. Recognition of DNB as a critical forest disease dates from the 1950s, when DNB spread in radiata pine (Pinus radiata) plantations in South America, New Zealand, and Africa (Gibson 1972). Historically, DNB had minor impacts in Northern America on native pines (Gibson 1972; Harrington and Wingfield 1998). However, in recent decades, DNB became 
more prevalent and has caused considerable tree mortality in western Canada (Woods 2003). In rare cases, DNB even caused the mortality of mature lodgepole pine stands and failure of entire plantations. Previous studies have related the DNB epidemic to a high concentration of young susceptible hosts (Woods 2003) and climate change, especially the increase in local summer precipitation (Woods et al. 2005).

Our present knowledge regarding plant defense mechanisms mainly comes from angiosperms, which cope with pathogen attack via multiple strategies. Pre-established structures and chemical synthetic mechanisms, such as cell walls, waxy epidermal cuticles, bark, and primary and secondary metabolites, serve as constitutive defenses. If the pathogen breaches constitutive defenses, induced defenses can be triggered, including multiple layers of innate immune responses. Plants rely on pathogen-associated molecular patterns (PAMPs) to recognize pathogens and give rise to PAMP-triggered immunity (PTI) (Macho and Zipfel 2014). Following pathogen detection, a series of signaling pathways are activated as defensive mechanisms, including $\mathrm{Ca}^{2+}$ bursts, reactive oxygen species (ROS) burst, and the mitogen-activated protein kinase (MAPK) pathway (Bigeard et al. 2015). Besides the basal resistance from PTI, plants can recognize pathogens via pathogen effectors, which are delivered by the pathogen to the plant cell to suppress PTI, referred to as effector-triggered immunity (ETI) (Jones and Dangl 2006). If a plant possesses disease resistance $(R)$ genes and produces $\mathrm{R}$ proteins, the corresponding effectors can be recognized, and ETI response may be activated (Cui et al. 2015), which is often associated with hypersensitive response (HR), a form of programmed cell death. Most $R$ genes code for proteins belonging to the nucleotide binding-leucine rich repeat (NB-LRR) family. Although angiosperms and gymnosperms diverged over 300 million years ago (Ran et al. 2018), orthology relationships can be resolved for many genes, with approximately $65 \%$ of lodgepole pine genes having a reasonably high-confidence ortholog identified in Arabidopsis (Yeaman et al. 2014), thus, we may use the knowledge from functional genomics for model angiosperms to infer disease resistance mechanisms in conifers.

The antagonistic interaction between plants and pathogens drives a coevolutionary process in which the plant evolves to recognize the pathogen and resist the attack, while the pathogen evolves to avoid the plant defense systems (Dodds et al. 2006; Kanzaki et al. 2012). Under the selective pressure exerted by pathogens, plant $R$ genes may undergo high numbers of amino acid replacements and contain substantial protein variants (Bakker et al. 2006). Previous studies have revealed several modes of selection to explain the nucleotide diversity of $R$ genes. Positive selection signatures were detected in the LRR regions of $R$ genes in Arabidopsis thaliana (Mondragón-Palomino et al. 2002). Studies on other $R$ gene families of Arabidopsis species suggested different evolutionary mechanisms, like a few instances of natural selection in defensin-like genes and contrasting patterns of purifying and diversifying selection in NOD-like receptor genes (MondragónPalomino et al. 2017). Recent studies have suggested that balancing selection maintains the genetic variation of plant immunity genes (Gos et al. 2012; Hörger et al. 2012; Koenig et al. 2019).

For gymnosperms, we have accumulated limited information to date about pathogen recognition and response. Norway spruce exhibited a potential abscisic acid signaling pathway to defend against infection by the fungal pathogen Heterobasidion annosum (Kovalchuk et al. 2019). In western white pine (Pinus monticola), positive selection might drive divergence of PR-10 proteins (Liu and Ekramoddoullah 2004). RNA-sequencing (RNA-seq) analyses of western white pine needles infected by the white pine blister rust Cronartium ribicola suggested that genes encoding disease resistance protein homologs, abscisic acid receptor, and transcription factors might be involved in pathogen resistance (Liu et al. 2013). These studies provide some understanding of the genetic basis of disease resistance in gymnosperm species through experimental manipulations and genomics, but there is still much to learn. One aspect of response that has been recognized more recently is that, under biotic stress, some genes do not show differences in mRNA level but produce different proteins due to pre-mRNA splicing. Comparing differential exon usage (DEU) events between treatments can help us not only understand alternative splicing (AS) but, also, the use of alternative transcript start sites and polyadenylation sites (Anders et al. 2012). However, we lack studies on DEU patterns of gymnosperms in response to a pathogen.

In this study, we tested the hypothesis that tolerant lodgepole pine trees can induce expression of defense genes more strongly than susceptible lodgepole pine trees in response to the fungal pathogen $D$. septosporum. We aimed to identify i) key genes differentially expressed during the lodgepole pine$D$. septosporum interaction, ii) evolutionary processes that drive the pathogen resistance, and iii) candidate $R$ genes that correspond to D. septosporum effectors. Our study provides insight into the resistance mechanisms of lodgepole pine to D. septosporum and promotes the development of tools that can be used to manage DNB outbreaks in lodgepole pine.

\section{RESULTS}

Infection rate of lodgepole pine seedlings.

To quantify infection level, we rated the percentage of symptomatic needles in each seedling that was inoculated with D. septosporum isolate D1 or D2. We selected these two isolates for the experiment because they belong to two isolated genetic lineages that diverged between 45,000 and 17,000 years ago, coinciding with the last glacial maximum (Capron et al. 2020). We found a significant difference between seedlings from tolerant parents and those from susceptible parents $(F$ value $=7.01 ; P$ value $<0.01)$, with seedlings from tolerant parents having fewer symptomatic needles than those from susceptible parents (Fig. 1A and 1B). Variance analysis indicated no interaction between the D. septosporum isolate (D1 or D2) and host family (tolerant or susceptible) $(F$ value $=$ $1.78 ; P$ value $=0.18)$

\section{Differential gene expression patterns between tolerant and susceptible pines.}

We identified differentially expressed genes (DEGs) and DEU events under each treatment, which included tolerant and susceptible pines, different fungal isolates, and different timepoints. The lodgepole pine reference transcriptome included 27,371 genes, with 15,385 genes annotated with gene ontology (GO) terms and 7,959 genes with Kyoto Encyclopedia of Genes and Genomes (KEGG) orthology (KO) terms. Gene expression patterns differed between susceptible and tolerant pines, D. septosporum isolates, and harvest times (Fig. 2A). In the multidimensional scaling (MDS) plot (Supplementary Fig. S1), dimension 1 separated the samples harvested at 4 days postinoculation (dpi) from those harvested at 8 and 12 weeks postinoculation (wpi), while dimension 2 roughly separated tolerant from susceptible pines. Most DEGs occurred in tolerant samples at $4 \mathrm{dpi}$, with much stronger responses to $D$. septosporum isolate 2 (D2) than to D. septosporum isolate 1 (D1). Another peak of DEGs occurred in susceptible samples inoculated with D1 harvested at 12 wpi. Few DEGs overlapped across different treatments or across different harvest timepoints (Supplementary Fig. S2). Overall, we found little evidence of DEU, 
with most significant DEU events occurring in the samples inoculated with D1 (Fig. 2B). D2 did not trigger pronounced DEU events, and there was no overlap between DEGs and genes containing DEU under the same treatment.

To examine potential functions of the identified genes, we tested for enrichment of GO and KO terms among DEGs and genes containing DEU events. For DEGs, tolerant samples inoculated with D2 at 4 dpi and susceptible samples inoculated with D1 at 12 wpi had the most enriched GO and KO terms (Fig. 3 and 4). GO term microbody (GO: 0042579) had the most DEGs, followed by other GO terms including aromatic amino acid family catabolic process (GO: 0009074), carbonoxygen lyase activity (GO: 0016838), and iron ion binding (GO: 0005506). KO term cytochrome P450 had the most DEGs, followed by other KO terms including plant-pathogen interaction and MAPK signaling pathway. For genes containing DEU events, we only tested enriched GO terms, as there were too few KO terms annotated. Enriched GO terms for genes containing DEU events include glucose-1-phosphate adenylyltransferase activity (GO: 0008878), ribulose-bisphosphate carboxylase activity (GO: 0016984), phosphotransferase activity (GO: 0016780) (Supplementary Table S1).

We found signatures of constitutive and induced defense genes related to cell structure and chemical compounds from the enriched GO terms for DEGs (Fig. 3). The GO: 0042579 microbody, also called peroxisomes, are the eukaryotic organelles and sole sites of fatty acid $\beta$-oxidation in plant cells. Peroxisomes are involved in producing active jasmonates, which are phytohormones regulating stress responses and development (Hu et al. 2012). The GO: 0009074 aromatic amino acid family catabolic process includes the chemical reactions and pathways resulting in the breakdown of aromatic amino acids tyrosine, phenylalanine, and tryptophan (Parthasarathy et al. 2018), which are linked to the synthesis of various secondary metabolites following pathogen infection (Hahlbrock et al. 2003). The GO: 0016838 carbon-oxygen lyase participates in the synthesis of these three aromatic amino acids. Plants rely on membrane trafficking pathways, the secretory and endocytic pathways ( $\mathrm{Gu}$ et al. 2017), to direct targeted protein transport and coordinated membrane dynamics. The secretory pathway is used to deliver defense proteins and metabolites with antimicrobial activities to the extracellular space (Wang et al. 2016). The endocytic pathway is required by plant immunity mediated by pattern recognition receptor kinases (Mbengue et al. 2016). We identified enriched GO terms that are involved in plant-pathogen interaction via membraneregulated activities such as GO: 0015810 aspartate transmembrane transport and GO: 0099132 ATP hydrolysis coupled cation transmembrane transport. The production of ROS at the cell surface (i.e., oxidative burst) may play multiple roles in plant immunity, such as induction of HR and MAPK cascade (Yoshioka et al. 2008). The identified GO: 0005506 iron ion binding is likely to provide adequate iron levels to activate oxidative burst (Ye et al. 2014).

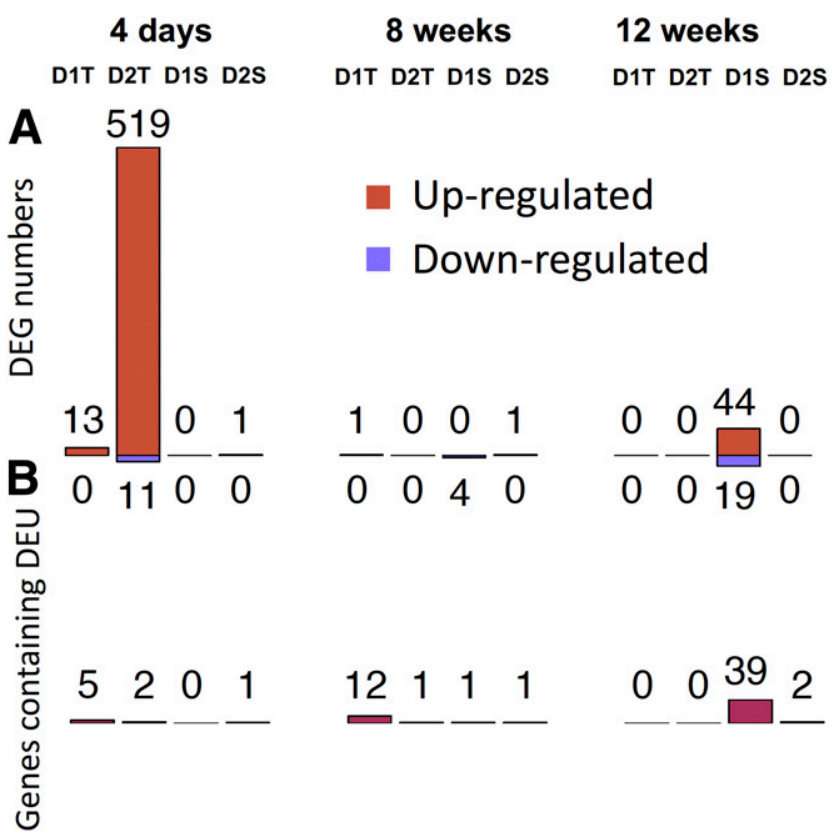

Fig. 2. A, Numbers of differentially expressed genes (DEGs) and B, genes containing differential exon usage (DEU) events under each treatment. The significant DEGs and DEU were defined as those with a false discovery rate $<0.05 . \mathrm{T}=$ tolerant lodgepole pine samples, $\mathrm{S}=$ susceptible lodgepole pine samples, D1 = Dothistroma septosporum isolate $1, \mathrm{D} 2=$ D. septosporum isolate 2,4 days $=4$ days postinoculation, 8 weeks $=8$ weeks postinoculation (wpi), and 12 weeks $=12 \mathrm{wpi}$.
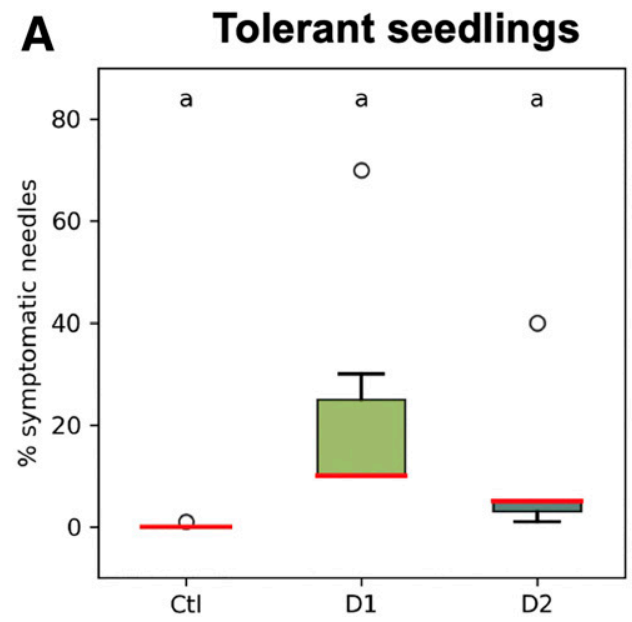

\section{B Susceptible seedlings}

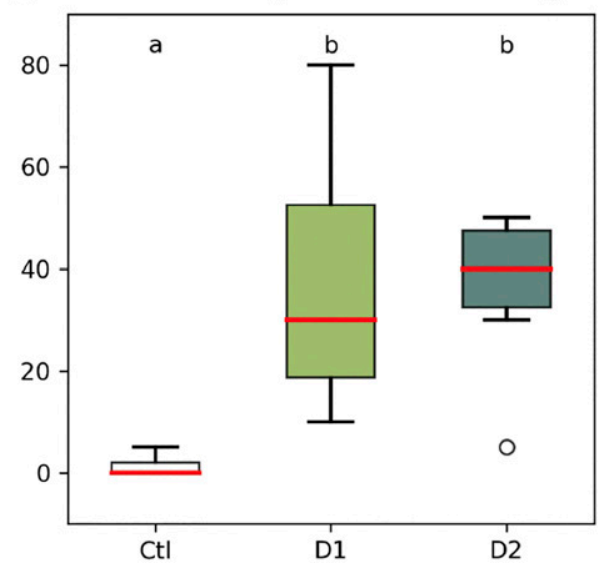

Fig. 1. Infection rate of lodgepole pine seedlings from $\mathbf{A}$, tolerant and $\mathbf{B}$, susceptible parents. Seedlings were inoculated with Dothistroma septosporum isolate 1 (D1) or D. septosporum isolate 2 (D2). Control seedlings (Ct1) were inoculated with water. The numbers of samples rated for tolerant seedlings are five for $\mathrm{Ctl}$, seven inoculated with D1, and seven inoculated with D2; the numbers of samples rated for susceptible seedlings are seven for Ctl, six inoculated with D1, and six inoculated with D2. In each panel, boxplot means that share the same letter are not significantly different $(P$ value $>0.05)$ according to Tukey's honestly significant difference test. 


\section{Coexpressed gene modules related to $D$. septosporum infection phenotypes.}

We found increased expression of plant defense genes and decreased expression of photosynthetic genes by constructing coexpressed gene modules. We identified 18 gene modules among susceptible samples, with each module containing 47 to 2,968 genes, and 23 gene modules among tolerant samples, with each module containing 40 to 2,935 genes. The consensus network, which is a common pattern of coexpressed genes among both susceptible and tolerant samples, included 22 gene modules with each module containing 47 to 2,568 genes.

We related the eigengene values of each gene module to D. septosporum infection phenotypes (D1, D2, and control). We found six tolerant gene modules related to D. septosporum isolate, with a stronger response to D2 than to D1, but we did not find any susceptible gene modules related to D. septosporum isolate. Four modules were up-regulated (Fig. 5, T_Modules $1,2,5$, and 6) and two modules were down-regulated (Fig. 5, T_Modules 3 and 4) relative to controls. The enriched GO terms for genes contained in D. septosporum-related gene modules (Supplementary Table S2) indicated that upregulated gene modules mainly represented clusters of genes related to plant defense functions, such as jasmonic acid mediated signaling pathway (GO: 0009867), chitinase activity (GO: 0004568), and ubiquitin protein ligase activity (GO:0061630). The downregulated gene modules mainly represented clusters of genes related to photosynthetic functions, such as photosynthesis (GO:0015979) and chlorophyll binding (GO: 0016168). Of the 544 DEGs identified in tolerant samples, 235 DEGs were present in D. septosporum-associated gene modules, 132 DEGs were present in D. septosporum-nonassociated modules, while the remaining 177 DEGs were not present in gene modules.
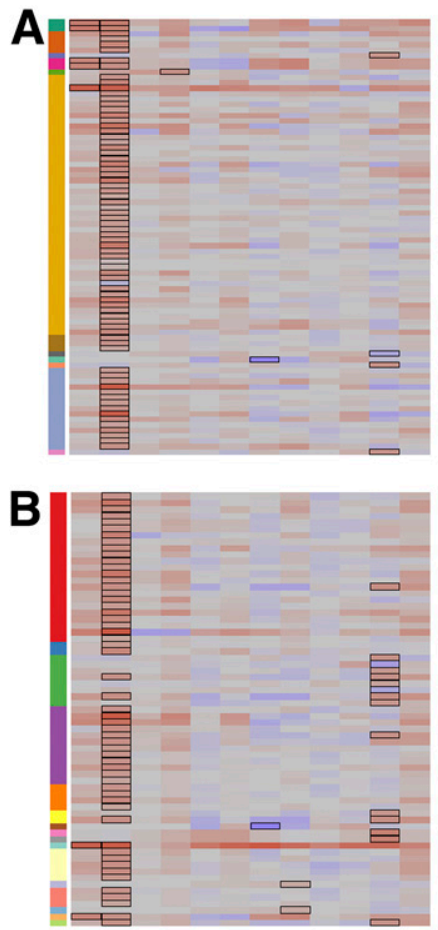

\section{Cellular component}

actin cytoskeleton GO:0015629 clathrin-coated vesicle GO:0030136 cytosol GO:0005829 extracellular space GO:0005615 integral component of membrane GO:001602 microbody GO:0042579 nitochondrial proton-transporting ATP synthase, catalytic core GO:0005754 nuclear pore GO:0005643 nucleosome GO:0000786 pore complex GO:0046930 vacuolar membrane GO:0005774

Biological process

\section{aromatic amino acid family catabolic process GO:0009074 aspartate transmembrane transport GO:0015810 ATP hydrolysis coupled cation transmembrane transport GO:0099132 ATP synthesis coupled proton transport GO:0015986} detoxification of copper ion GO:0010273 induced systemic resistance, jasmonic acid mediated signaling pathway GO:0009864 isopentenyl diphosphate biosynthetic process, mevalonate pathway GO:0019287 negative regulation of defense response to insect GO:1900366 priming of cellular response to stress GO:0080136 protein metabolic process GO:001953 response to chitin GO:0010200 esponse to endogenous stimulus GO:0009719 response to karrikin GO:0080167 response to oxidative stress GO:0006979 tryptophan transport GO:0015827

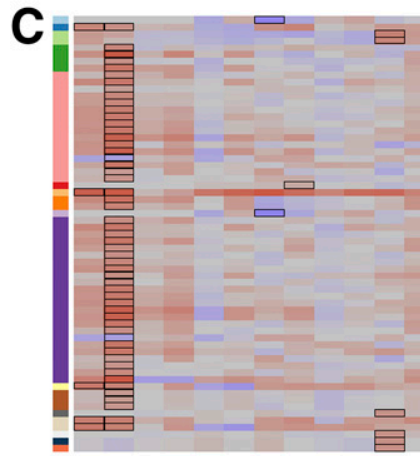

\section{Molecular function}

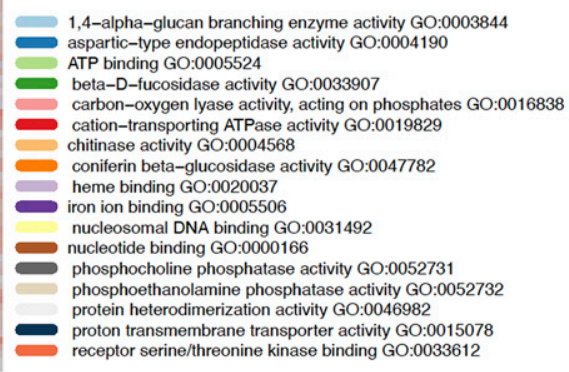

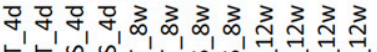

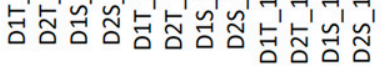

Fig. 3. Enriched gene ontology (GO) terms for genes that were differentially expressed (DEGs) under at least one of the treatments. The bordered cells show which genes were identified as DEGs under the specific treatments. DEGs were identified by comparing expression levels of Dothistroma septosporuminoculated samples (T and S) with those of control samples at each harvest timepoint. DEGs with positive or negative logtwofold change (logFC) values were classified as upregulated $(\log \mathrm{FC}>0)$ or downregulated $(\log \mathrm{FC}<0)$, respectively. Bars on the left with different colors represent GO terms. There are three categories of GOs: A, cellular component, $\mathbf{B}$, biological process, and $\mathbf{C}$, molecular function. $\mathrm{T}=$ tolerant lodgepole pine samples, $\mathrm{S}=$ susceptible lodgepole pine samples, D1 $=$ D. septosporum isolate $1, \mathrm{D} 2=$ D. septosporum isolate $2,4 \mathrm{~d}=4$ days postinoculation, $8 \mathrm{w}=8 \mathrm{weeks}$ postinoculation $(\mathrm{wpi})$, and $12 \mathrm{w}=12$ wpi. 


\section{Inferred lodgepole pine-D. septosporum interaction pathway suggests PTI and ETI.}

To infer the signaling pathway of lodgepole pine in response to D. septosporum attack, we mapped the $\mathrm{KO}$ terms attached to the identified genes (DEGs and genes contained in coexpressed gene modules associated with $D$. septosporum infection phenotypes) to the plant-pathogen interaction reference pathway (PATHWAY: ath04626) deposited in the KEGG database (Fig. $6)$. For all the KO terms attached to the identified genes, we found $26 \mathrm{KO}$ terms are present in the plant-pathogen interaction pathway. These $26 \mathrm{KO}$ terms were attached to 43 genes that were all identified from tolerant samples. Four of the 43 genes were DEGs, 31 were genes contained in modules, and eight genes were both DEGs and genes in modules. According to the pathway functions, we found most identified genes were involved in the perception of pathogens by PTI, such as genes encoding calcium-dependent protein kinase, brassinosteroid insensitive 1-associated receptor kinase, somatic embryogenesis receptor kinase, WRKY transcription factor, pathogenesisrelated genes transcriptional activator, and EIX receptor. We also found genes involved in ETI, such as genes encoding enhanced disease susceptibility protein. Besides the 43 identified genes, there are 130 lodgepole pine genes that were also annotated with $\mathrm{KO}$ terms related to plant-pathogen interaction, but these 130 genes were not identified through our top-down methods (DEGs or coexpressed gene modules [Supplementary Table S3]).

\section{Expression levels of DEGs identified from tolerant samples correlated with evolutionary rates.}

We calculated evolutionary rates of protein-coding genes using the PAML codeml pairwise comparison method (Fig. 7A;
Supplementary Fig. S3). The most pronounced pattern with respect to evolutionary rate was in DEGs identified from tolerant samples, in which $d_{\mathrm{N}} / d_{\mathrm{S}}$ ratios, $d_{\mathrm{N}}$, and $d_{\mathrm{S}}$ values were significantly higher than those in non-DEGs (Table 1; Supplementary Table S4). We also found pronounced patterns of reduced evolutionary rate in genes contained in pathogenassociated modules (coexpressed gene modules related to D. septosporum infection phenotypes), where $d_{\mathrm{N}} / d_{\mathrm{S}}$ ratios, $d_{\mathrm{N}}$, and $d_{\mathrm{S}}$ values were lower than those not contained in pathogen associated modules (Table 1; Supplementary Table S4). Genes residing in the plant-pathogen interaction pathway had higher $d_{\mathrm{S}}$ values but lower $d_{\mathrm{N}} / d_{\mathrm{S}}$ ratios than genes not residing in the plant-pathogen interaction pathway. Among susceptible samples, $d_{\mathrm{N}}$ values of DEGs were higher than those of non-DEGs. But we did not observe a significant difference in $d_{\mathrm{N}} / d_{\mathrm{S}}$ ratios between DEGs and non-DEGs among susceptible samples. We found expression levels of DEGs identified from tolerant samples significantly correlated with $d_{\mathrm{N}} / d_{\mathrm{S}}$ ratios (Fig. 7B, correlation coefficient $=0.22, P$ value $=0.01$ ), but this correlation was not significant among susceptible samples (Fig. 7C, correlation coefficient $=0.20, P$ value $=0.41)$. We discarded genes containing DEU for the evolutionary rate comparison, as there were too few genes.

We also detected sites under positive selection, using the branch-site model of the PAML codeml module. We aligned the genes from lodgepole pine, loblolly pine (Pinus taeda), sugar pine (Pinus lambertiana), and Douglas fir (Pseudotsuga menziesii) and identified 3,707 orthologous gene groups. We identified 249 lodgepole pine genes with sites under positive selection. The functions of these genes are summarized in Table 2 (Supplementary Table S5 includes the functions of all genes). We did not find evidence that genes with sites under

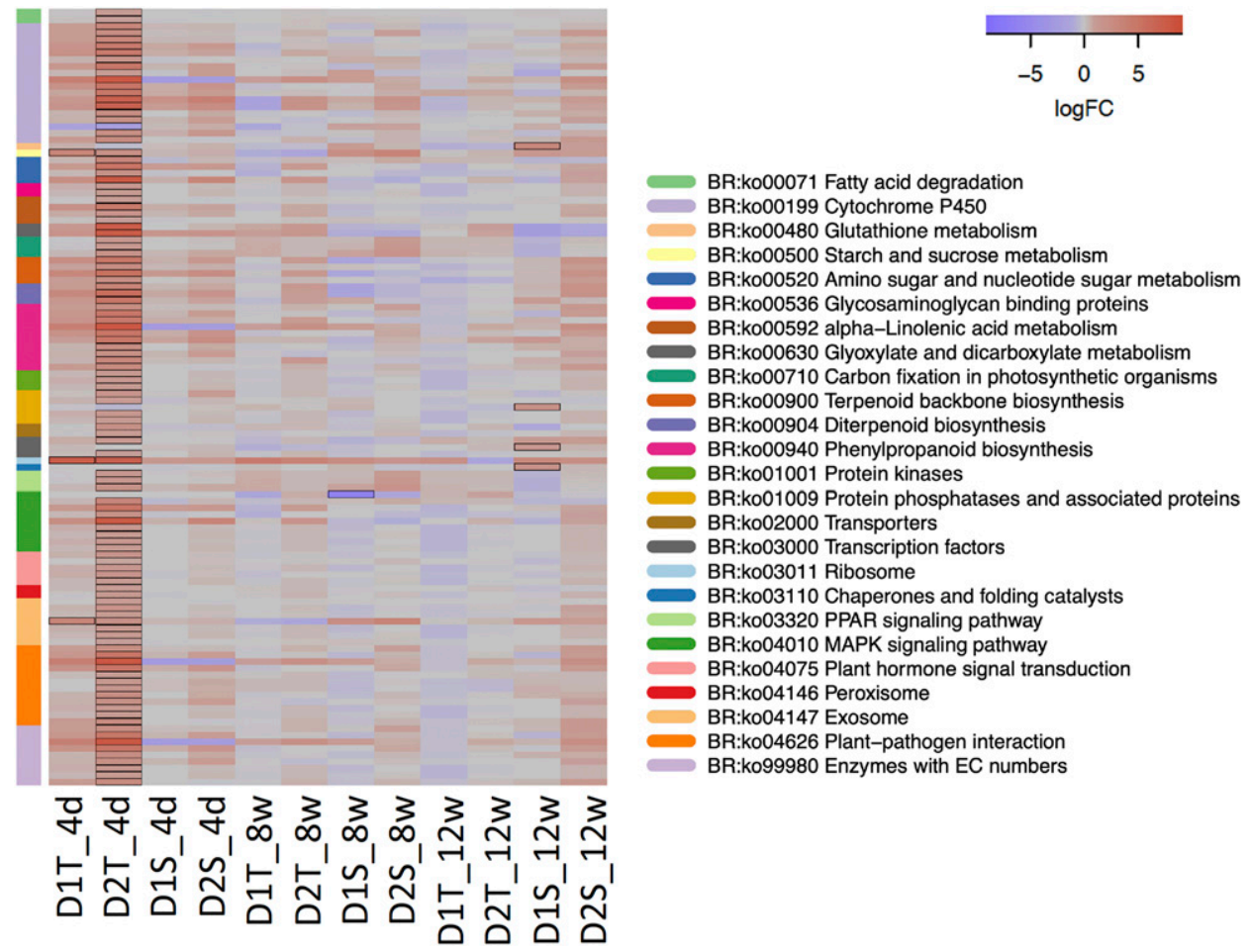

Fig. 4. Enriched Kyoto Encyclopedia of Genes and Genomes (KEGG) orthology terms for genes that were differentially expressed (DEGs) under at least one of the treatments. The bordered cells show which genes were identified as DEGs under the specific treatments. DEGs were identified by comparing expression levels of Dothistroma septosporum-inoculated samples (T and S) with those of control samples at each harvest timepoint. DEGs with positive or negative $\log$ twofold change $(\log \mathrm{FC})$ values were classified as upregulated $(\log \mathrm{FC}>0)$ or downregulated $(\log \mathrm{FC}<0)$, respectively. KEGG objects are organized into a functional hierarchy with four levels from A to D. We only presented C level terms in the heatmap. $\mathrm{T}=$ tolerant lodgepole pine samples, $\mathrm{S}=$ susceptible lodgepole pine samples, D1 $=$ D. septosporum isolate $1, \mathrm{D} 2=$ D. septosporum isolate $2,4 \mathrm{~d}=4$ days postinoculation, $8 \mathrm{w}=8$ weeks postinoculation (wpi), and $12 \mathrm{w}=12 \mathrm{wpi}$ 
positive selection were enriched among the identified genes in the plant-pathogen interaction pathway, DEGs, or pathogen associated modules.

Candidate $\boldsymbol{R}$ genes were expressed under pathogen attack.

We found nine genes with disease resistance functions carried positive selection signals (Table 3). Genes ref16_comp10495_c0, ref16_comp30462_c0, and ref16_comp5119_c1 had a high proportion $(0.10 \sim 0.40)$ of sites under positive selection compared with other genes $(0.01 \sim 0.03)$. The identified conserved domains included NB-ARC, LRRs, and coiled-coil domains, which are signatures of plant $\mathrm{R}$ proteins. None of these candidate $R$ genes were identified as DEGs. However, the expression profiles between inoculated and control
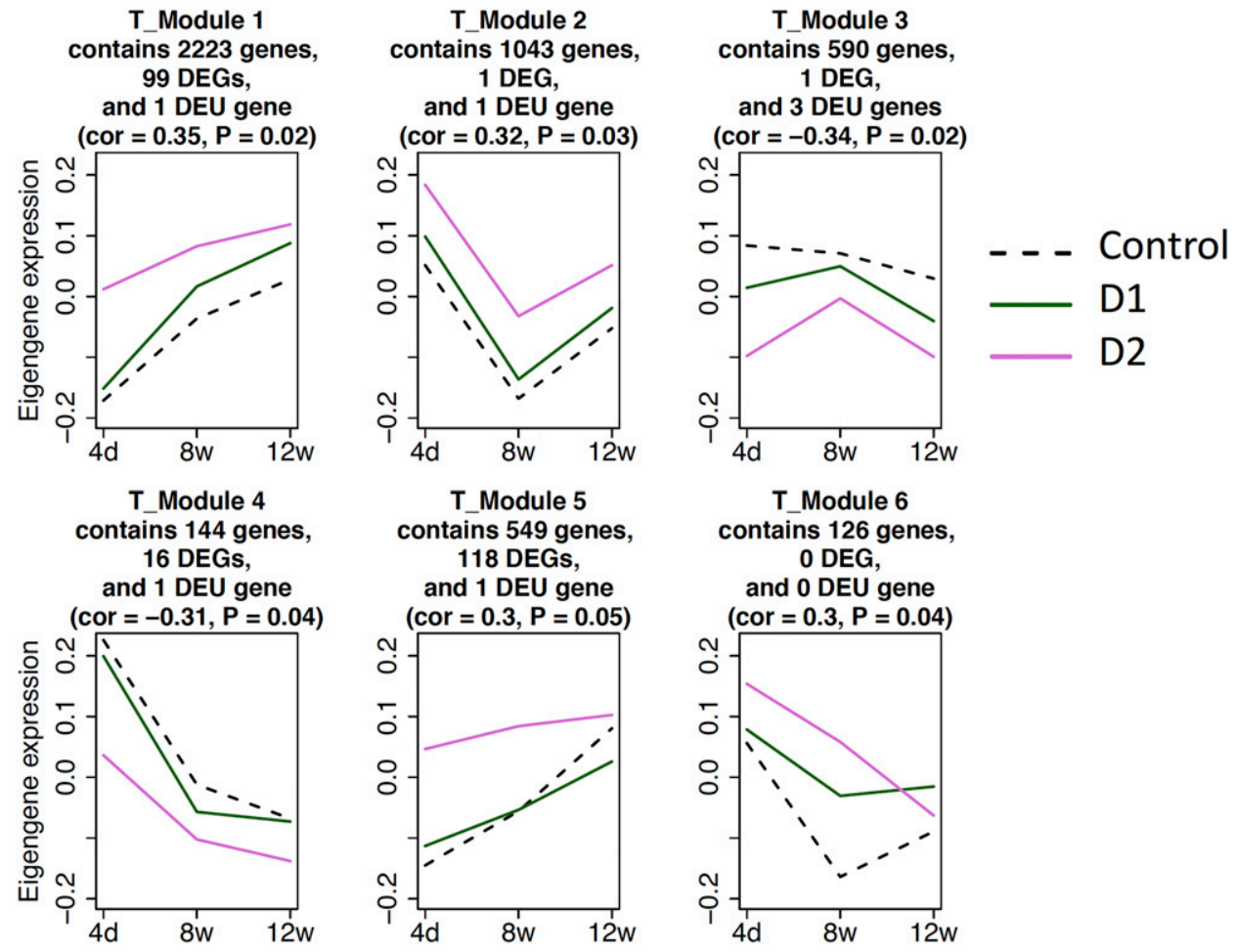

Fig. 5. Eigengene expression profiles. The shown gene modules were identified from tolerant samples and they were related to Dothistroma septosporum infection phenotypes. $\mathrm{T}=$ tolerant lodgepole pine samples, $\mathrm{D} 1=D$. septosporum isolate $1, \mathrm{D} 2=D$. septosporum isolate 2 , Control $=$ no $D$. septosporum inoculation, $4 \mathrm{~d}=4$ days postinoculation, $8 \mathrm{w}=8$ weeks postinoculation (wpi), and $12 \mathrm{w}=12 \mathrm{wpi}$.

PAMP-triggered immunity

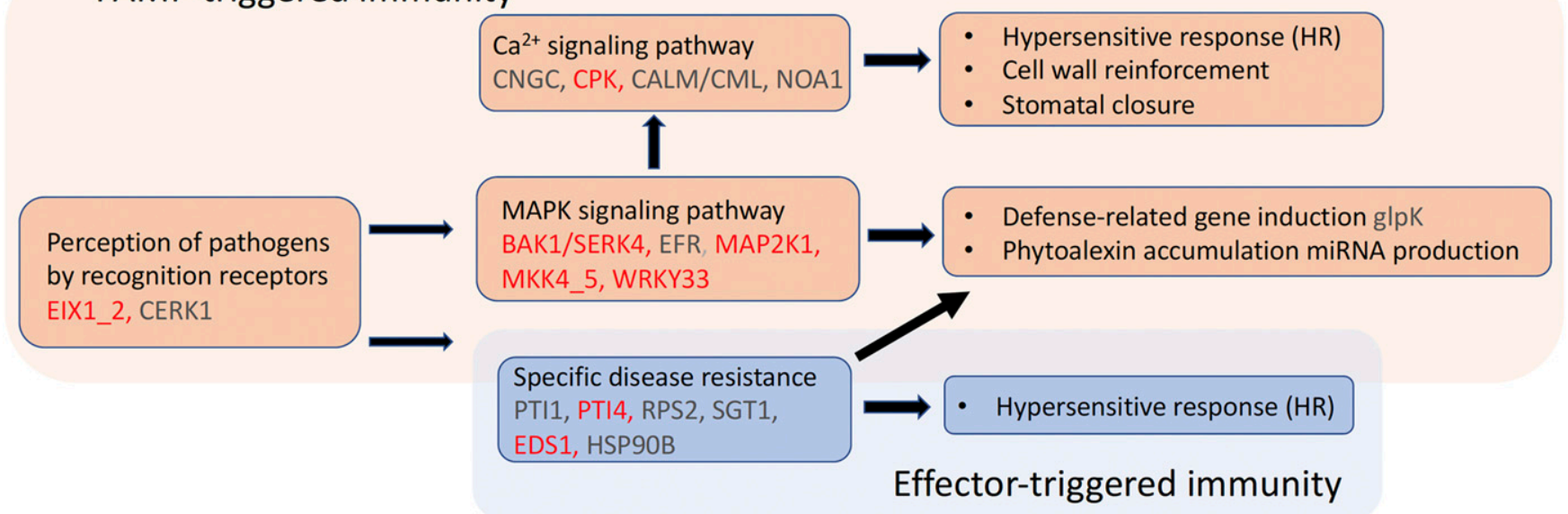

Fig. 6. Inferred lodgepole pine-Dothistroma septosporum interaction pathway using Kyoto Encyclopedia of Genes and Genomes orthology terms identified from tolerant samples. Gene symbols highlighted in red are differentially expressed genes (DEGs). Gene symbols in gray are in coexpressed gene modules associated with $D$. septosporum infection phenotypes. The gene symbols represent identified genes residing in signaling pathways. $\mathrm{Ca}^{2+}$ signaling pathway: $\mathrm{CNGC}=$ cyclic nucleotide gated channel, $\mathrm{CPK}=$ calcium-dependent protein kinase, $\mathrm{CALM}=$ calmodulin, $\mathrm{CML}=$ calcium-binding protein, NOA1 $=$ nitricoxide synthase; mitogen-activated protein kinase (MAPK) signaling pathway: BAK1 = brassinosteroid insensitive 1-associated receptor kinase 1, SERK4 = somatic embryogenesis receptor kinase 4, EFR = leucine-rich repeat receptor-like serine/threonine-protein kinase, MAP2K1 = MAPK kinase 1, MKK4_5 = MAPK kinase 4/5, WRKY33 = WRKY transcription factor 33, glpK = glycerol kinase; perception of pathogens by recognition receptors: EIX1_2 = EIX receptor 1/2, CERK1 = chitin elicitor receptor kinase 1; specific disease resistance: PTI1 = Pto-interacting protein 1 , PTI $4=$ pathogenesis-related genes transcriptional activator, RPS2 = disease resistance protein, SGT1 = suppressor of G2 allele of SKP1, EDS1 = enhanced disease susceptibility 1 protein, HSP90B = heat shock protein $90 \mathrm{kDa}$ beta. 
samples, represented by logtwofold change (logFC) and counts per million, showed these candidate $R$ genes were up- or downregulated at certain harvest timepoints (Fig. 8; Supplementary Fig. S5; Supplementary Table S6), suggesting their different responses to the pathogen. When comparing the rank of these candidate $R$ genes relative to that of background genes, some showed a consistent gene expression pattern (Supplementary Fig. S6). For example, the gene ref16_comp32598_c0, which contains NB-ARC, LRR domains, was highly up-regulated among tolerant samples inoculated with D1 or D2 but downregulated among susceptible samples.

\section{DISCUSSION}

Deploying genetic resistance against pathogens is one of the most promising and sustainable methods to manage plant diseases. Most agricultural crops have extensive breeding programs to select varieties with resistance alleles. Breeding trees for disease resistance is more complicated due to a long cycle for producing resistant genetic material. In the present study, we compared the gene expression pattern between tolerant and susceptible lodgepole pines (Pinus contorta) and identified key genes putatively involved in the lodgepole pine-
D. septosporum interaction. We also identified candidate $R$ genes that contained signatures of selection and are likely the product of adaptation to the pathogen.

We found a rapid and strong transcriptomic response in tolerant lodgepole pines to inoculation with D2, in contrast to a late and weak response in susceptible samples to D1. We identified a time series in transcriptomic response, with the highest gene expression at the earliest sampling point after inoculation. This pattern is similar to that found in another experimental study that showed a time series of $D$. septosporum gene expression through its infection cycle of the host Pinus radiata (Bradshaw et al. 2016). Researchers obtained extremely few fungal reads at early ( 3 weeks) and mid stages ( 8 weeks) of infection relative to a late stage ( 12 weeks). The fungal gene expression showed a clear stage-specific pattern, like upregulation of genes encoding fungal cell wall-modifying enzymes at the early stage and upregulation of genes for secondary metabolism at the late stage. Taken together, these studies suggest a time series of crosstalk between lodgepole pine defense and $D$. septosporum infection, which is likely linked to the hemibiotrophic lifestyle of D. septosporum (Kabir et al. 2015), whose infection strategy transits from asymptomatic biotrophic infection to destructive necrotrophic infection. It
A

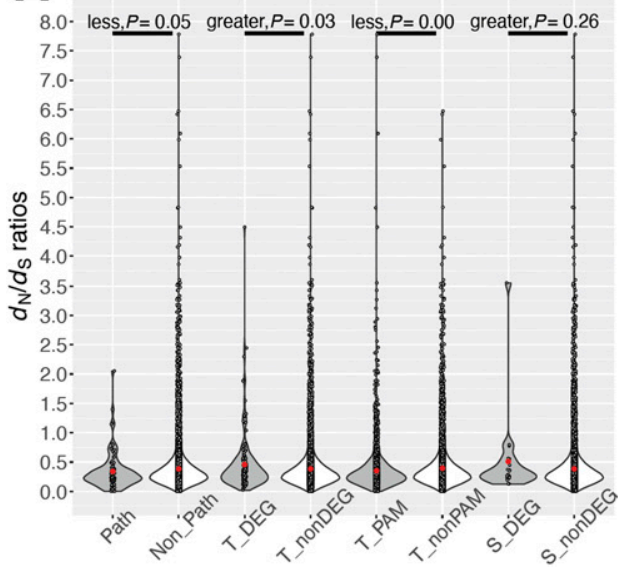

B

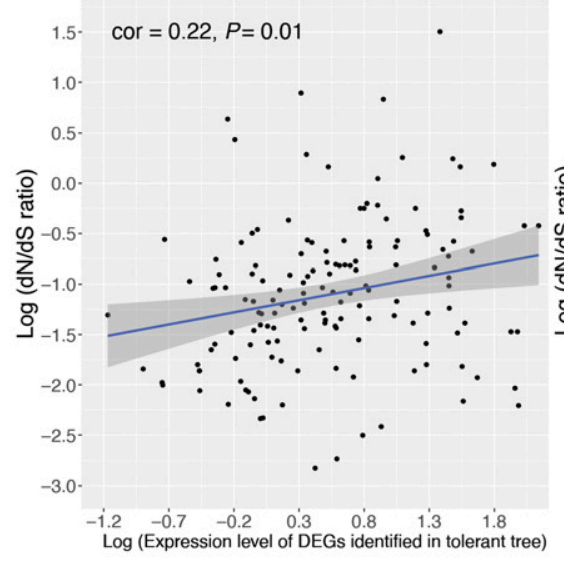

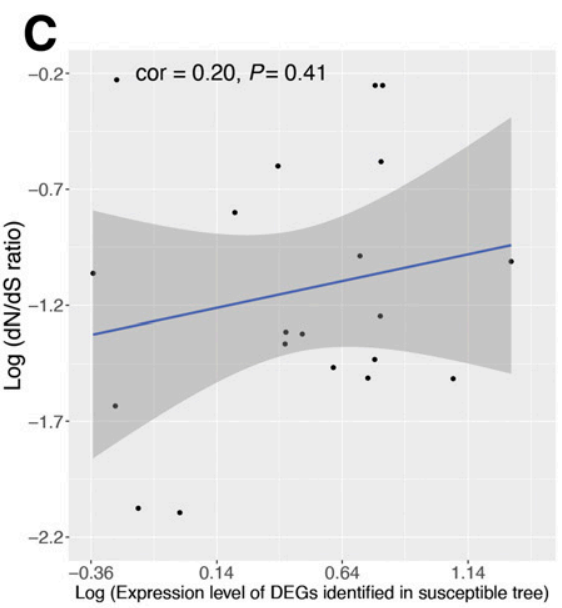

Fig. 7. A, Distribution of $d_{\mathrm{N}} / d_{\mathrm{S}}$ ratios. Red spots represent the mean values of $d_{\mathrm{N}} / d_{\mathrm{S}}$ ratios within a gene group. The $d_{\mathrm{N}} / d_{\mathrm{S}}$ ratios of genes in two complementary groups were compared by conducting a one-tailed Wilcoxon rank sum test. Path = genes residing in plant-pathogen pathway $(n=87)$, Non_path $=$ genes not residing in plant-pathogen pathway $(n=10,035), T \_D E G=$ genes identified as differentially expressed genes (DEGs) in tolerant samples $(n=149), T_{-}$nonDEG $=$ genes identified as not differentially expressed in tolerant samples $(n=9,973)$, T_PAM $=$ genes identified in pathogen-associated modules $(n=2,838)$, T_nonPAM = genes not identified in pathogen-associated modules $(n=7,284)$, S_DEG $=$ genes identified as differentially expressed in susceptible samples $(n$ $=20)$, and S_nonDEG $=$ genes not identified as differentially expressed in susceptible samples $(n=10,102)$. $\mathbf{B}$ and $\mathbf{C}, d_{\mathrm{N}} / d_{\mathrm{S}}$ as a function of expression level of DEGs in tolerant and susceptible samples, respectively. Black dots represent DEGs. The smooth line shows the linear regression between log-transformed gene expression level and log-transformed $d_{\mathrm{N}} / d_{\mathrm{S}}$ ratios.

Table 1. Gene numbers and mean values of $d_{\mathrm{N}} / d_{\mathrm{S}}, d_{\mathrm{N}}$, and $d_{\mathrm{S}}$ within complementary gene groups ${ }^{\mathrm{a}}$

\begin{tabular}{|c|c|c|c|c|c|c|c|c|}
\hline Gene category & Path & Non_Path & T_DEG & T_nonDEG & T_PAM & T_nonPAM & S_DEG & S_nonDEG \\
\hline Gene number & 87 & 10,035 & 149 & 9,973 & 2,838 & 7,284 & 20 & 10,102 \\
\hline $\begin{array}{l}d_{\mathrm{N}} / d_{\mathrm{S}} \text { mean } \\
\quad\left(d_{\mathrm{N}} / d_{\mathrm{S}} \text { range }\right)\end{array}$ & $0.34^{\mathrm{b}}(0-2.05)$ & $0.38(0-7.78)$ & $0.46^{\mathrm{c}}(0.02-4.50)$ & $0.38(0-7.78)$ & $0.35^{\mathrm{b}}(0-7.78)$ & $0.40(0-6.47)$ & $0.51(0.12-3.55)$ & $0.38(0-7.78)$ \\
\hline $\begin{array}{l}d_{\mathrm{N}} \text { mean } \\
\quad\left(d_{\mathrm{N}} \text { range }\right)\end{array}$ & $0.06(0-0.69)$ & $0.06(0-1.99)$ & $0.10^{\mathrm{c}}(0-1.30)$ & $0.06(0-1.99)$ & $0.04^{\mathrm{b}}(0-1.59)$ & $0.07(0-1.99)$ & $0.06^{\mathrm{c}}(0.01-0.44)$ & $0.06(0-1.99)$ \\
\hline $\begin{array}{l}d_{\mathrm{S}} \text { mean } \\
\quad\left(d_{\mathrm{S}} \text { range }\right)\end{array}$ & $0.17^{\mathrm{c}}(0.03-1.97)$ & $0.15(0.01-2)$ & $0.24^{\mathrm{c}}(0.02-1.97)$ & $0.15(0.01-2)$ & $0.12^{\mathrm{b}}(0.01-1.95)$ & $0.17(0.01-2)$ & $0.17(0.01-0.80)$ & $0.15(0.01-2)$ \\
\hline
\end{tabular}

${ }^{\mathrm{a}}$ Path = genes residing in plant-pathogen interaction pathway, Non_path = genes not residing in plant-pathogen interaction pathway, $\mathrm{T} \_\mathrm{DEG}=$ genes identified as differentially expressed genes (DEGs) in tolerant samples, T_nonDEG = genes not identified as differentially expressed in tolerant samples, T_PAM $=$ genes identified in pathogen-associated modules, $\mathrm{T}_{-}$nonPAM $=$genes not identified in pathogen-associated modules, $\mathrm{S}_{-} \mathrm{DEG}=$ genes identified as differentially expressed in susceptible samples, amd S_nonDEG = genes not identified as differentially expressed in susceptible samples.

${ }^{\mathrm{b}}$ Gene group with a significantly lower rank than the complementary gene group, by one-tailed Wilcoxon rank sum test for comparing distribution of $d_{\mathrm{N}} / d_{\mathrm{S}}$, $d_{\mathrm{N}}$, and $d_{\mathrm{S}}$ values within complementary gene groups $(P$ value cut-off threshold $=0.05)$.

c Gene group with a significantly higher rank than the complementary gene group by one-tailed Wilcoxon rank sum test for comparing distribution of $d_{\mathrm{N}} / d_{\mathrm{S}}$, $d_{\mathrm{N}}$, and $d_{\mathrm{S}}$ values within complementary gene groups $(P$ value cut-off threshold $=0.05)$. 
seems different genes were activated in lodgepole pine and D. septosporum during biotrophy-necrotrophy transition.

We analyzed posttranscription changes by comparing DEU events between treatments. A major type of DEU is AS. A study on Arabidopsis infected with the bacterial pathogen Pseudomonas syringae found that more than $44 \%$ of multiexon genes showed evidence of AS events (Howard et al. 2013). In plant pathogen defense, AS was putatively involved in regulating different proteins, such as pattern recognition receptor proteins (Sanabria and Dubery 2016), plant disease R proteins (Yang et al. 2014), and WRKY transcription factors (Liu et al. 2016). Since the identified DEU-containing genes did not overlap with DEGs within any treatments and most DEU-containing genes were triggered by D1 while most DEGs were triggered by D2 (Fig. 2), it seems gene expression and exon usage act differently in response to D. septosporum attack.

The coexpressed gene module analysis can give some clues about how groups of genes regulate lodgepole pine response to D. septosporum and suggests a potential growth and defense trade-off pattern. Downregulation of photosynthetic genes commonly occurs in plants under biotic attack according to previous comparative transcriptome analyses (Bilgin et al. 2010), which may be because ETI induces prolonged activation of MAPK, thus inhibiting photosynthesis (Su et al. 2018).

We inferred an innate immune pathway, including PTI and ETI, by mapping the KO terms attached to the identified genes to the KEGG plant-pathogen interaction reference pathway

Table 2. Functions of genes with sites under positive selection

\begin{tabular}{|c|c|}
\hline Gene_category ${ }^{\mathbf{a}}$ & Gene function \\
\hline Path & $\begin{array}{l}\text { Leucine-rich repeat resistance protein; EF-hand } \\
\text { calcium-binding domain profile; cleavage site for } \\
\text { pathogenic type III effector avirulence factor }\end{array}$ \\
\hline T_DEG & $\begin{array}{l}\text { Ubiquitin/SUMO-activating enzyme; UDP- } \\
\text { glycosyltransferase; calcium-binding protein; EF-hand } \\
\text { calcium-binding domain; cytochrome P450; } \\
\text { mitochondrial carrier protein }\end{array}$ \\
\hline T_PAM & $\begin{array}{l}\text { Ubiquitin/SUMO-activating enzyme; ABC transporter } \\
\text { family; auxin-induced protein; ribulose-1,5- } \\
\text { bisphosphate carboxylase/oxygenase activase; } \\
\text { cytochrome P450; amidophosphoribosyltransferase; } \\
\text { mitogen-activated protein kinase; Sugar transport } \\
\text { proteins }\end{array}$ \\
\hline S_DEG & Beta-glucosidase glycosyl hydrolase \\
\hline
\end{tabular}

from Arabidopsis thaliana (Fig. 6). The inferred pathways, which were involved in PTI and ETI, suggest that lodgepole pine recognizes $D$. septosporum attack through a chitin receptor (CERK1) and triggers a series of downstream signaling response, including a $\mathrm{Ca}^{2+}$ burst and the MAPK cascade, which lead to cell-wall reinforcement, stomatal closure, and HR. The specific disease resistance proteins (PTI1, PTI4, RPS2) can contribute to detection of the pathogen-secreted effector proteins, followed by activation of plant defense genes, induction of pathogen-specific immune response, HR, and programmed cell death. This inferred lodgepole pine-D. septosporum interaction pathway suggests lodgepole pine and Arabidopsis thaliana may share a similar set of components comprising the innate immunity pathway.

We inferred the selection pressures on protein-coding genes by calculating evolutionary rate $\left(d_{\mathrm{N}} / d_{\mathrm{S}}\right)$. We found genes contained in coexpressed gene modules and in the plant-pathogen interaction pathway had a lower evolutionary rate than those not contained in the modules or pathway (Fig. 7A). Previous studies have indicated positions and the connectivity of the genes and their products in pathways may influence evolutionary rates (Alvarez-Ponce et al. 2009; Mähler et al. 2017). In a protein network, substitutions in one protein result in selection pressure for reciprocal change on its interacting partner protein, so the highly interacting proteins evolve slowly (Fraser et al. 2002; Fumasoni and Murray 2020; Guin and Gruebele 2019). Additionally, upstream genes undergo a greater selective constraint than downstream genes, possibly due to the pleiotropic functions of upstream genes for a wide range of end products (Hämälä et al. 2020; Olson-Manning 2020; Ramsay et al. 2009). Our result aligns with previous studies, showing that genes that comprise pathways may undergo strong selection so that they can coordinate with other genes to perform functions.

Our observation of high evolutionary rates in DEGs identified from tolerant pines is contrary to previous studies on expressed genes of different tissue types, such as buds and needles from Populus trichocarpa, Picea abies, and Picea glauca, which showed highly expressed genes were associated with slow-evolving protein sequences (De La Torre et al. 2015; Ingvarsson 2007). Our study suggests highly expressed pathogen resistance genes could be favored by higher evolutionary rates to counteract $D$. septosporum attacks.

We identified candidate $R$ genes with sites under positive selection. Plants and pathogens are locked into reciprocal coevolution; a pathogen evolves its alleles of avirulence (effector) genes to escape recognition by plant $R$ genes, while plants counterattack by evolving their alleles of $R$ genes to adapt to the divergence of pathogen (Bergelson et al. 2001). As a result,

Table 3. Candidate resistance genes that were identified with sites under positive selection

\begin{tabular}{|c|c|c|c|c|}
\hline \multirow[b]{2}{*}{ Gene ID } & \multirow[b]{2}{*}{$P$ value $^{\mathbf{a}}$} & \multicolumn{2}{|c|}{ Sites under positive selection } & \multirow[b]{2}{*}{ Conserved domains $^{b}$} \\
\hline & & Proportion & Number & \\
\hline ref16_comp18426_c0 & $<0.00$ & 0.02 & 3 & RPW8 super family; NB-ARC super family \\
\hline ref16_comp10495_c0 & $<0.00$ & 0.10 & 74 & NB-ARC super family \\
\hline ref16_comp32598_c0 & 0.00 & 0.01 & 7 & $\begin{array}{l}\text { NB-ARC super family; RX-CC_like; LRR; } \\
\text { PLN00113 super family }\end{array}$ \\
\hline ref16_comp11037_c0 & 0.03 & 0.01 & 6 & PLN00113 super family \\
\hline ref16_comp30462_c0 & $<0.00$ & 0.28 & 42 & PLN03210 super family \\
\hline ref16_comp11412_c1 & $<0.00$ & 0.11 & 15 & PLN03210 super family; TIR super family \\
\hline ref16_comp5119_c1 & 0.01 & 0.40 & 41 & PLN00113 super family \\
\hline ref16_comp24947_c0 & 0.00 & 0.03 & 6 & LRR \\
\hline ref16_comp2939_c0 & $<0.00$ & 0.01 & 4 & STKc_IRAK; PLN00113 super family \\
\hline
\end{tabular}


plant $R$ genes and pathogen avirulence genes both show high variability and often present a gene-for-gene recognition specificity due to their coevolution. For example, the pathogen Magnaporthe oryzae avirulence gene AVR-Pik physically binds the N-terminal coiled-coil domain of the rice $R$ gene $P i k$ in a yeast two-hybrid assay (Kanzaki et al. 2012). In this study, we identified nine candidate $R$ genes that contained sites under positive selection. Three genes had a high proportion of sites under positive selection, indicating selective sweeps near the beneficial alleles. These sites under positive selection are located close to conserved domains of $R$ genes, indicating their important roles in recognizing pathogen effector genes (Sueldo et al. 2015).

Pathogen effectors induce differential $R$ gene expression to trigger disease resistance (Gu et al. 2005). The up- and downregulation patterns of the identified candidate $R$ genes indicate they can be activated or inhibited in response to D. septosporum attack. Some $R$ genes contain multiple alleles with differential resistance to pathogen races (Kanzaki et al. 2012). We found the gene ref16_comp32598_c0 was up-regulated by both D1 and D2 isolates among tolerant samples, possibly because this gene contains multiple domains that confer multiple recognition sites. However, we need to identify corresponding effectors and conduct molecular assays to confirm the functions of these candidate $R$ genes (Guo et al. 2020).

Our study provides genetic resources to understand lodgepole pine-D. septosporum interaction, and the identified genes may be useful candidates in the development of genomic or marker-based selection approaches to accelerate lodgepole pine breeding to reduce the impacts of $D$. septosporum infection.

\section{MATERIALS AND METHODS}

Plants, fungal strains, culture, and inoculation conditions.

The tolerant and susceptible lodgepole pine (Pinus contorta) samples used in this study were created by crossing parent trees that were ranked for foliage retention in the presence of Dothistroma septosporum. The progeny test site was planted in the year 2000 near Kispiox, British Columbia, Canada. The test included 121 families (117 wind-pollinated families and four full-sib families) and eight wild-stand seedlots. The test was established using a randomized complete block design with eight blocks, and families were planted in four-tree row plots within each block. Infection by $D$. septosporum was confirmed by a field pathologist prior to assessment. Each tree was assessed at age 12 for the percent of foliage retention on a scale of 0 (complete defoliation) to $100 \%$ (complete foliage retention). At this site, trees at age 12 should have foliage at ground level (100\% foliage retention), because crown closure has not yet occurred. D. septosporum infection in the lower crown of trees will cause foliage loss, thus assessing the percent of foliage retention is a good indication of the ability of a tree to tolerate D. septosporum. The mean foliage retention of the 121 families on site was $48 \%$ (ranged from 34 to $66 \%$ ) and the mean of the eight wild seedlots was $49 \%$. A model was run to test the difference between family means using the R package lmer (Bates et al. 2015). This model incorporated families as fixed effects, blocks and block $\times$ family as random effects, and foliage retention at age 12 of all trees in the 125 open pollinated families and seedlots (117 wind-pollinated families and eight wild-stand seedlots) as the dependent variable. A multiple comparison test was performed using the Tukey's adjustment implemented by the $\mathrm{R}$ package emmeans (Lenth 2020). We found a significant difference $(P$ value $<0.00)$ between two families with high foliage retention and two families with low foliage retention. Two parents of families (exposed to D. septosporum in a field trial) with high foliage retention were crossed and two with low foliage retention were crossed to create the tolerant and susceptible families used for this study. The offspring of the two tolerant parent trees had a mean foliage retention of $60 \%$, and the offspring of the two susceptible parent trees had a mean foliage

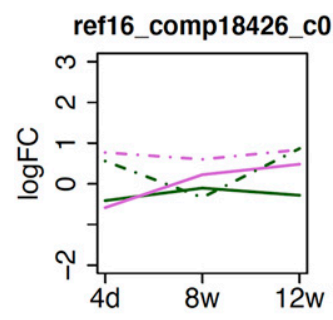

ref16_comp11037_c0

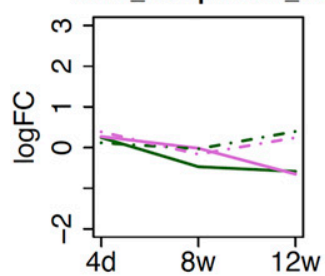

ref16_comp5119_c1

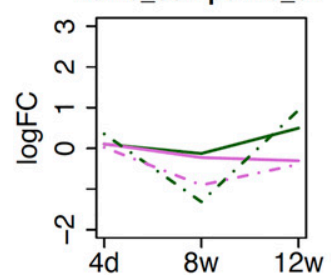

ref16_comp10495_c0

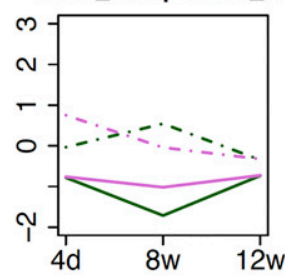

ref16_comp30462_c0

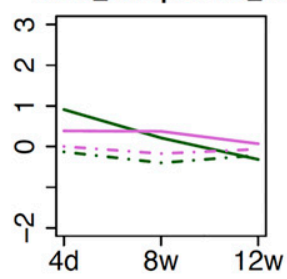

ref16_comp24947_c0

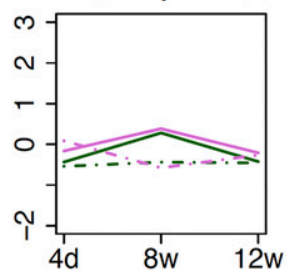

ref16_comp32598_c0

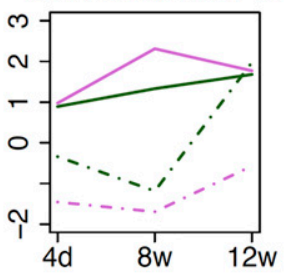

ref16_comp11412_c1

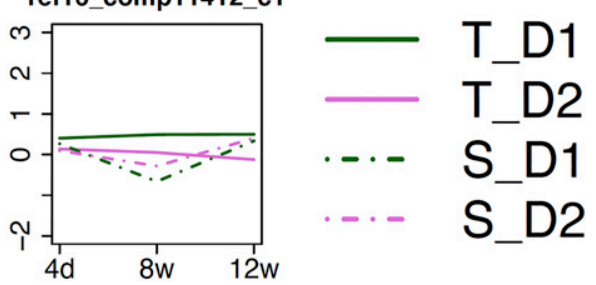

ref16_comp2939_c0

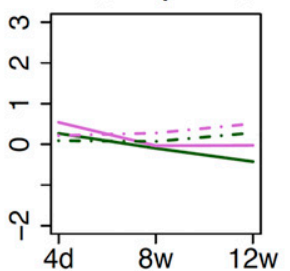

Fig. 8. Expression profiles of the nine identified candidate resistance $(R)$ genes. Expression was measured by logtwofold change (logFC) values when comparing Dothistroma septosporum-inoculated samples with control samples at each harvest timepoint, using edgeR. None of these candidate $R$ genes were identified as differentially expressed genes under the false discovery rate threshold of $0.05 . \mathrm{T}=$ tolerant lodgepole pine samples, $\mathrm{S}=$ susceptible lodgepole pine samples, D1 $=$ D. septosporum isolate $1, \mathrm{D} 2=D$. septosporum isolate $2,4 \mathrm{~d}=4$ days postinoculation, $8 \mathrm{w}=8$ weeks postinoculation $(\mathrm{wpi}), 12 \mathrm{w}=12 \mathrm{wpi}$. 
retention of $41 \%$. The controlled crosses were made in Orchard 230 at the Kalamalka Seed Orchard in Vernon, British Columbia, Canada. Seeds from crossed families were harvested and were used to produce seedlings that were inoculated in our experiment. Seedlings from tolerant parents were named as T and those from susceptible parents as $\mathrm{S}$.

$\mathrm{T}$ and $\mathrm{S}$ seedlings, between 1 and 2 years old, were inoculated with two D. septosporum isolates (D1 and D2) separately with four to six replicates. D1 was isolated from infected hybrid $P$. contorta $\times P$. banksiana in Alberta, Canada, while D2 was isolated from infected $P$. contorta in Smithers, British Columbia, Canada. D. septosporum conidia were harvested from colonies grown for 10 to 16 days on Dothistroma sporulation medium plates (Bradshaw et al. 2000) by suspension in sterile distilled water. Each seedling was inoculated with a standard inoculum of approximately $3 \mathrm{ml}$ of suspension of $1.6 \times 10^{6}$ conidia per milliliter, using a household trigger action atomizer. The plants were left on the inoculation bench until the needles were dry (approximately $45 \mathrm{~min}$ ), were then wrapped in transparent plastic bags, and were placed in a growth chamber (16 h daylight at $20^{\circ} \mathrm{C}, 8 \mathrm{~h}$ night at $12^{\circ} \mathrm{C}$ ) for $48 \mathrm{~h}$. A mister spraying tap water was activated every hour for $3 \mathrm{~min}$ for the duration of the trial, to maintain needle wetness. Control seedlings that were inoculated with water were also prepared. Seedlings were rated according to the level of disease observed on a linear scale from 0 to $100 \%$ of symptomatic needles, i.e., necrotic needles with either red bands, fruiting bodies, or both at the end of the experiment (12 wpi). The numbers of samples rated for tolerant seedlings are Control $=5$, inoculated with $\mathrm{D} 1=7$, inoculated with $\mathrm{D} 2=7$; the numbers of samples rated for susceptible seedlings are Control $=7$, inoculated with D1 $=6$, inoculated with D2 $=6$. Samples for RNA-seq were taken at $4 \mathrm{dpi}, 8$, and $12 \mathrm{wpi}$, when fungal surface growth, new immature lesions, and sporulating lesions were expected or observed (Supplementary Table S7). Eight to twelve necrotic needles with disease lesions were preferentially sampled. Needles were flash frozen in liquid nitrogen and were stored at $-80^{\circ} \mathrm{C}$.

\section{RNA extraction and RNA-seq.}

Total RNA was extracted from frozen needles. Needles were manually ground in liquid nitrogen using a mortar and pestle, and approximately $60 \mathrm{mg}$ of powdered tissue was used for the RNA extraction. Total RNA was extracted from each of 90 samples, using the Spectrum plant total RNA kit (Sigma Aldrich, St. Louis) in a random order with respect to treatment to avoid batch effects. After eliminating traces of genomic DNA by treatment with On-Column DNase I digest set (Sigma Aldrich), RNA quality was evaluated using an automated capillary gel electrophoresis and quantity was assessed using a Bioanalyzer 2100 with RNA 6000 Nano Labchips (Agilent Technologies, Santa Clara, CA, U.S.A.). A260/A280 and A260/A230 ratios were measured using a Nanodrop fluorometer (Nanodrop Products, Wilmington, DE, U.S.A.). Total RNA concentration was determined by Qubit 2, using the Qubit RNA HS assay kit (Invitrogen, Thermo Fisher Scientific, Waltham, MA, U.S.A.). For all the samples, the A260/A280 ratios were 1.94 or higher, A260/A230 ratios were 1.2 or higher, with the RNA integrity number ranging from 6.8 to 8.0. Standard paired end 100-bp Illumina RNA-seq libraries were prepared using NEB mRNA stranded library preparation kits (New England Biolabs, Ipswich, MA, U.S.A.), at Centre d'expertise et de services Génome Québec, and were sequenced on five lanes of an Illumina HiSeq4000 instrument.

\section{Transcriptome assembly and annotation.}

Raw reads were processed with FASTX-Toolkit (available online), including clipping adaptors, filtering artifacts, and keeping reads with a minimum quality score of 20 . De novo transcriptome assembly was performed using Trinity v2.5.1 (Grabherr et al. 2011) with an input file gathering reads from the library with the highest number of reads for each of the 18 treatments. The de novo assembled transcripts were then aligned to a previous lodgepole pine transcriptome (Yeaman et al. 2014) using blastn v2.9.0 with an E value threshold of 1e10. Newly assembled transcripts that could be aligned to the previous transcriptome were removed, and the remaining transcripts were added to the previously assembled transcriptome. This combined transcriptome was further examined to filter out low-expression and contaminant genes. Filtered RNA-seq reads (from each of the 90 libraries) were mapped to the combined transcriptome using the software RSEM v1.2.25 with default parameters (Li and Dewey 2011). Transcripts with high expression levels were identified from RSEM mapping output as those having a transcript per million (TPM) value $\geq 1.00$ in all replicates of any sample type ( $\mathrm{T}$ or $\mathrm{S}$ or control) at any harvest timepoint per D. septosporum isolate.

To remove any eventual contamination, the combined transcriptome was aligned against the nonredundant (nr) protein database (downloaded on March 24, 2018) using the blastx function and "-more-sensitive" mode implemented by the software DIAMOND v0.9.19.120 (Buchfink et al. 2015). Query transcripts with high similarity (E value threshold of 1e-10) to the green plant subjects were then selected. Additionally, the combined transcriptome was aligned against the loblolly pine reference genome (Neale et al. 2014), using the software GMAP v2017-06-20 (Wu and Watanabe 2005) to identify transcripts with high similarity (identity $\geq 75 \%$ and coverage $\geq 75 \%$ ) to the loblolly pine genes. Transcripts with high similarity to green plants or loblolly pine subjects were combined into one single file. To remove redundant genes, the longest isoform with a length $\geq 300 \mathrm{bp}$ for each gene was selected, and transcripts with high expression levels (TPM value $\geq 1.00$ ) were retained. Putative D. septosporum genes were removed from the combined transcriptome if the transcripts could be assigned to "Dothistroma" or "Dothideomycetidae" in a blastx search against the $\mathrm{nr}$ database or if the transcripts could be aligned to the D. septosporum reference genome (de Wit et al. 2012) with a high similarity (identity $\geq 50 \%$ and coverage $\geq 50 \%$ ), using GMAP v2017-06-20. At the end, we obtained a lodgepole pine reference transcriptome that includes 27,371 transcripts.

To annotate the lodgepole pine reference transcriptome with GO and KEGG terms, the transcripts were translated to protein sequences using TransDecoder (available online) and were then annotated using eggNOG v4.5 (Huerta-Cepas et al. 2016), InterProScan v5.30-69.0 (Jones et al. 2014), and Blast2Go v5.1 (Götz et al. 2008). All annotations were combined. To make a uniform KEGG annotation format, EC numbers were converted to KOs according to the hierarchical text file, which was downloaded from the KEGG database. We deposited the lodgepole pine transcriptome and annotation files generated in this study in the Dryad Digital Repository.

\section{Gene analyses.}

MDS plot was used to visualize differences between the expression profiles of different samples using the $\mathrm{R}$ package edgeR (Robinson et al. 2010). To identify DEGs, D. septosporuminoculated samples ( $\mathrm{T}$ and $\mathrm{S}$ ) were compared with control samples at each harvest timepoint. DEGs were defined as those with a false discovery rate $<0.05$ by computing differential expression using edgeR. DEGs with positive or negative $\operatorname{logFC}$ values were classified as upregulated $(\operatorname{logFC}>0)$ or downregulated $(\operatorname{logFC}$ $<0$ ), respectively. The overlapped DEGs across different treatments were detected using the online Bioinformatics Venn diagram tool Calculate and draw custom Venn diagrams. 
We investigated the changes in relative exon usage caused by each treatment. The 27,371 transcripts were aligned against the loblolly pine reference genome (Neale et al. 2014), using GMAP v2017-06-20 to acquire a gene annotation file. Reads from each library were aligned to the loblolly pine reference genome using TopHat v2.1.1 with default parameters (Kim et al. 2013). To identify differential exon usage, D. septosporuminoculated samples ( $\mathrm{T}$ or $\mathrm{S}$ ) were compared with control samples at each harvest timepoint, using the $\mathrm{R}$ package DEXSeq (Anders et al. 2012).

Coexpressed gene module analysis was performed using the R package WGCNA (Langfelder and Horvath 2008). Only genes with a mean fragments per kilobase million value $>10$ were used for construction of gene modules. Gene modules were identified from $\mathrm{T}$ and $\mathrm{S}$ samples. Then summary gene module profiles (eigengenes) were related to D. septosporum phenotypes D1, D2, and control.

Enriched GO terms of each category (biological process, molecular function, cellular component) were separately detected using the "weight" algorithm with the Fisher ratio test implemented by the R package topGO (Alexa and Rahnenfuhrer 2018). Enriched KEGG terms were detected using the hypergeometric method implemented by the $\mathrm{R}$ package plyr (Wickham 2011). The expression profiles of the DEGs along with their enriched GO or KEGG terms were used to plot heatmaps using the $\mathrm{R}$ package gplots (Warnes et al. 2016).

Previous studies have identified genes involved in PTI and ETI of plant-pathogen interaction pathway (ath04626). In the present study, we annotated 173 genes with KO terms related to the plant-pathogen interaction (Arabidopsis thaliana) pathway.

\section{Comparison of evolutionary rates within different gene groups.}

We calculated evolutionary rate of protein-coding genes, represented by the ratio of nonsynonymous substitutions per nonsynonymous site to synonymous substitutions per synonymous site $\left(d_{\mathrm{N}} / d_{\mathrm{S}}\right)$, using the codeml module of PAML v4.9i (Yang 2007). To do this, transcriptome of sugar pine (Pinus lambertiana; in Pinus subgenus strobus), a related species to lodgepole pine, was downloaded from the TreeGenes database. This sugar pine transcriptome contains 33,113 transcripts. We identified candidate coding regions within transcript sequences of sugar pine and lodgepole pine using TransDecoder. A total of 10,401 orthologous gene groups (with a minimum length of 20 amino acids) were identified between lodgepole pine and sugar pine, using the software Proteinortho v6.0.2 (Lechner et al. 2011). The coding sequences for genes within these orthologous gene groups were aligned using the software ClustalW v2.1 with default parameters (Larkin et al. 2007). These alignments were used as input to run the codeml pairwise model to obtain $d_{\mathrm{N}} / d_{\mathrm{S}}$ ratios, $d_{\mathrm{N}}$, and $d_{\mathrm{S}}$ values with the following parameters: for null model: runmode $=-2$, CodonFreq $=$ 2 , model $=0$, NSsites $=0$, fix_omega $=1$, omega $=1$; for alternative model: runmode $=-2$, CodonFreq $=2$, model $=0$, NSsites $=0$, fix_omega $=0$, omega $=1$. To prevent a false estimate of $d_{\mathrm{N}} / d_{\mathrm{S}}$ for gene alignments with too similar or too divergent sequences, alignments resulting in $d_{\mathrm{N}} / d_{\mathrm{S}}>10$ or $d_{\mathrm{S}}<$ 0.01 or $d_{\mathrm{N}}>2$ or $d_{\mathrm{S}}>2$ were discarded (Anisimova et al. 2003). After filtering, we obtained $d_{\mathrm{N}} / d_{\mathrm{S}}$ ratios for 10,122 genes. We compared distributions of $d_{\mathrm{N}} / d_{\mathrm{S}}$ ratios using one-tailed Wilcoxon rank sum test (Mann and Whitney 1947). The graphs were plotted using the R package ggplot2 (Wickham 2016). All statistical analyses were performed in R (R Core Team 2018).

\section{Identification of candidate $\boldsymbol{R}$ genes.}

We identified genes with sites under positive selection using the codeml branch-site model in the PAML v4.9i software. In addition to the transcriptomes of lodgepole pine and sugar pine, transcriptomes of loblolly pine (Pinus taeda) and Douglas fir (Pseudotsuga menziesii) were downloaded from the TreeGenes database. A total of 3,732 orthologous groups including all four species were identified. The parameters of codeml branch-site model were set up as follows: for null model: runmode $=0$, CodonFreq $=2$, model $=2$, NSsites $=2$, fix_omega $=1$, omega $=1$; for alternative model: runmode $=0$, CodonFreq $=2$, model $=2$, NSsites $=2$, fix_omega $=0$, omega $=1$. Likelihood ratio test statistic (twice the difference of the log-likelihood was calculated between the null model and alternative model) was compared with the critical value from the $\chi^{2}$ distribution. The one-tailed Fisher's exact test (Fisher 1934) was computed to compare the difference in numbers of genes with sites under positive selection within complementary gene groups.

Among the identified genes with sites under positive selection, we found that nine genes were annotated as $R$ genes. We identified the conserved domains in these genes using the National Center for Biotechnology Information conserved domain search. The barcodeplot function implemented by the $\mathrm{R}$ package edgeR was used to highlight the rank of these candidate $R$ genes relative to those in the entire data set (Robinson et al. 2010).

\section{ACKNOWLEDGMENTS}

We thank Centre d'expertise et de services Génome Québec for sequencing service, University of Calgary Information Technologies for system support, the Research Oversight Committee of CoAdapTree Project for suggestions and help, P. Smets and C. Chourmouzis for technical assistance. Special gratitude goes to M. Carlson and J. Murphy, who were responsible for designing and establishing the field trials used to select the tolerant and susceptible trees for this study.

\section{AUTHOR-RECOMMENDED INTERNET RESOURCES}

Bioinformatics Venn diagram tool:

http://bioinformatics.psb.ugent.be/webtools/Venn

FASTX-Toolkit: http://hannonlab.cshl.edu/fastx_toolkit

KEGG Arabidopsis thaliana plant-pathogen interaction: https://www.genome.jp/kegg-bin/show_pathway? ath04626

KEGG pathway ath04626:

https://www.genome.jp/dbget-bin/www_bget?pathway+ath04626

National Center for Biotechnology Information conserved domain search page: https://www.ncbi.nlm.nih.gov/Structure/cdd/wrpsb.cgi

TransDecoder: https://github.com/TransDecoder/TransDecoder/wiki

TreeGenes website: https://treegenesdb.org

\section{LITERATURE CITED}

Alexa, A., and Rahnenfuhrer, J. 2018. topGO: Enrichment analysis for gene ontology. R package version 2.34.0. Bioconductor Open Source Software for Bioinformatics.

Alvarez-Ponce, D., Aguadé, M., and Rozas, J. 2009. Network-level molecular evolutionary analysis of the insulin/TOR signal transduction pathway across 12 Drosophila genomes. Genome Res. 19:234-242.

Anders, S., Reyes, A., and Huber, W. 2012. Detecting differential usage of exons from RNA-seq data. Genome Res. 22:2008-2017.

Anisimova, M., Nielsen, R., and Yang, Z. 2003. Effect of recombination on the accuracy of the likelihood method for detecting positive selection at amino acid sites. Genetics 164:1229-1236.

Bakker, E. G., Toomajian, C., Kreitman, M., and Bergelson, J. 2006. A genome-wide survey of $R$ gene polymorphisms in Arabidopsis. Plant Cell 18:1803-1818.

Bates, D., Mächler, M., Bolker, B., and Walker, S. 2015. Fitting linear mixed-effects models using lme4. J. Stat. Softw. 67:1-48.

Bergelson, J., Kreitman, M., Stahl, E. A., and Tian, D. 2001. Evolutionary dynamics of plant $R$-genes. Science 292:2281-2285.

Bigeard, J., Colcombet, J., and Hirt, H. 2015. Signaling mechanisms in pattern-triggered immunity (PTI). Mol. Plant 8:521-539.

Bilgin, D. D., Zavala, J. A., Zhu, J., Clough, S. J., Ort, D. R., and DeLucia, E. H. 2010. Biotic stress globally downregulates photosynthesis genes. Plant Cell Environ. 33:1597-1613. 
Bradshaw, R. E., Ganley, R. J., Jones, W. T., and Dyer, P. S. 2000. High levels of dothistromin toxin produced by the forest pathogen Dothistroma pini. Mycol. Res. 104:325-332.

Bradshaw, R. E., Guo, Y., Sim, A. D., Kabir, M. S., Chettri, P., Ozturk, I. K., Hunziker, L., Ganley, R. J., and Cox, M. P. 2016. Genome-wide gene expression dynamics of the fungal pathogen Dothistroma septosporum throughout its infection cycle of the gymnosperm host Pinus radiata. Mol. Plant Pathol. 17:210-224.

Buchfink, B., Xie, C., and Huson, D. H. 2015. Fast and sensitive protein alignment using DIAMOND. Nat. Methods 12:59-60.

Capron, A., Feau, N., Heinzelmann, R., Barnes, I., Benowicz, A., Bradshaw, R. E., Dale, A. L., Lewis, K., Owen, T., Reich, R., Ramsfield, T., Woods, A., and Hamelin, R. 2020. Signatures of post-glacial genetic isolation and human-driven migration in the Dothistroma needle blight pathogen in western Canada. Phytopathology. doi:10.1094/PHYTO-08-20-0350-FI Published online. doi.org/10.1094/PHYTO-08-20-0350-FI

Cui, H., Tsuda, K., and Parker, J. E. 2015. Effector-triggered immunity: From pathogen perception to robust defense. Annu. Rev. Plant Biol. 66: 487-511.

De La Torre, A. R., Birol, I., Bousquet, J., Ingvarsson, P. K., Jansson, S., Jones, S. J. M., Keeling, C. I., MacKay, J., Nilsson, O., Ritland, K., Street, N., Yanchuk, A., Zerbe, P., and Bohlmann, J. 2014. Insights into conifer giga-genomes. Plant Physiol. 166:1724-1732.

De La Torre, A. R., Lin, Y. C., Van de Peer, Y., and Ingvarsson, P. K. 2015. Genome-wide analysis reveals diverged patterns of codon bias, gene expression, and rates of sequence evolution in picea gene families. Genome Biol. Evol. 7:1002-1015.

de Vries, S., de Vries, J., von Dahlen, J. K., Gould, S. B., Archibald, J. M., Rose, L. E., and Slamovits, C. H. 2018. On plant defense signaling networks and early land plant evolution. Commun. Integr. Biol. 11:1-14.

de Wit, P. J. G. M., van der Burgt, A., Ökmen, B., Stergiopoulos, I., AbdElsalam, K. A., Aerts, A. L., Bahkali, A. H., Beenen, H. G., Chettri, P., Cox, M. P., Datema, E., de Vries, R. P., Dhillon, B., Ganley, A. R., Griffiths, S. A., Guo, Y., Hamelin, R. C., Henrissat, B., Kabir, M. S., Jashni, M. K., Kema, G., Klaubauf, S., Lapidus, A., Levasseur, A., Lindquist, E., Mehrabi, R., Ohm, R. A., Owen, T. J., Salamov, A., Schwelm, A., Schijlen, E., Sun, H., van den Burg, H. A., van Ham, R. C. H. J., Zhang, S., Goodwin, S. B., Grigoriev, I. V., Collemare, J., and Bradshaw, R. E. 2012. The genomes of the fungal plant pathogens Cladosporium fulvum and Dothistroma septosporum reveal adaptation to different hosts and lifestyles but also signatures of common ancestry. PLoS Genet. 8:e1003088.

Dodds, P. N., Lawrence, G. J., Catanzariti, A. M., Teh, T., Wang, C. I., Ayliffe, M. A., Kobe, B., and Ellis, J. G. 2006. Direct protein interaction underlies gene-for-gene specificity and coevolution of the flax resistance genes and flax rust avirulence genes. Proc. Natl. Acad. Sci. U.S.A. 103: 8888-8893.

Fisher, R. A. 1934. Statistical methods for research workers, 5th Ed. Oliver and Boyd, Edinburgh, U.K.

Fraser, H. B., Hirsh, A. E., Steinmetz, L. M., Scharfe, C., and Feldman, M. W. 2002. Evolutionary rate in the protein interaction network. Science 296:750-752.

Fryer, J. L. comp. 2018. Tree species distribution maps from Little's “Atlas of United States trees" series. In: Fire Effects Information System, U.S. Department of Agriculture, Forest Service, Rocky Mountatin Research Station, Fire Sciences Laboratory (Producer), Fort Collins, CO, U.S.A. Published online. https://www.fs.fed.us/database/feis/pdfs/Little/aa SupportingFiles/LittleMaps.html [92602].

Fumasoni, M., and Murray, A. W. 2020. The evolutionary plasticity of chromosome metabolism allows adaptation to constitutive DNA replication stress. eLife 9:e51963.

Gibson, I. A. S. 1972. Dothistroma blight of Pinus radiata. Annu. Rev. Phytopathol. 10:51-72.

Gos, G., Slotte, T., and Wright, S. I. 2012. Signatures of balancing selection are maintained at disease resistance loci following mating system evolution and a population bottleneck in the genus Capsella. BMC Evol. Biol. 12:152.

Götz, S., García-Gómez, J. M., Terol, J., Williams, T. D., Nagaraj, S. H., Nueda, M. J., Robles, M., Talón, M., Dopazo, J., and Conesa, A. 2008. High-throughput functional annotation and data mining with the Blast2GO suite. Nucleic Acids Res. 36:3420-3435.

Grabherr, M. G., Haas, B. J., Yassour, M., Levin, J. Z., Thompson, D. A., Amit, I., Adiconis, X., Fan, L., Raychowdhury, R., Zeng, Q., Chen, Z., Mauceli, E., Hacohen, N., Gnirke, A., Rhind, N., di Palma, F., Birren, B. W., Nusbaum, C., Lindblad-Toh, K., Friedman, N., and Regev, A. 2011. Full-length transcriptome assembly from RNA-Seq data without a reference genome. Nat. Biotechnol. 29:644-652.
Gu, K., Yang, B., Tian, D., Wu, L., Wang, D., Sreekala, C., Yang, F., Chu, Z., Wang, G. L., White, F. F., and Yin, Z. 2005. $R$ gene expression induced by a type-III effector triggers disease resistance in rice. Nature 435:1122-1125.

Gu, Y., Zavaliev, R., and Dong, X. 2017. Membrane trafficking in plant immunity. Mol. Plant 10:1026-1034.

Guin, D., and Gruebele, M. 2019. Weak chemical Interactions that drive protein evolution: Crowding, sticking, and quinary structure in folding and function. Chem. Rev. 119:10691-10717.

Guo, Y., Hunziker, L., Mesarich, C. H., Chettri, P., Dupont, P.-Y., Ganley, R. J., McDougal, R. L., Barnes, I., and Bradshaw, R. E. 2020. DsEcp2-1 is a polymorphic effector that restricts growth of Dothistroma septosporum in pine. Fungal Genet. Biol. 135:103300.

Hahlbrock, K., Bednarek, P., Ciolkowski, I., Hamberger, B., Heise, A., Liedgens, H., Logemann, E., Nürnberger, T., Schmelzer, E., Somssich, I.E., and Tan, J. 2003. Non-self recognition, transcriptional reprogramming, and secondary metabolite accumulation during plant/pathogen interactions. Proc. Natl. Acad. Sci. U.S. A. 100(Suppl 2):14569-14576.

Hämälä, T., Gorton, A. J., Moeller, D. A., and Tiffin, P. 2020. Pleiotropy facilitates local adaptation to distant optima in common ragweed (Ambrosia artemisiifolia). PLoS Genet. 16:e1008707.

Harrington, T. C., and Wingfield, M. J. 1998. Diseases and the ecology of indigenous and exotic pines. Pages 381-404 in: Ecology and Biogeography of Pinus. D. M. Richardson, ed. Cambridge University Press, Cambridge.

Hörger, A. C., Ilyas, M., Stephan, W., Tellier, A., van der Hoorn, R. A. L., and Rose, L. E. 2012. Balancing selection at the tomato RCR3 guardee gene family maintains variation in strength of pathogen defense. PLoS Genet. 8:e1002813.

Howard, B. E., Hu, Q., Babaoglu, A. C., Chandra, M., Borghi, M., Tan, X., He, L., Winter-Sederoff, H., Gassmann, W., Veronese, P., and Heber, S. 2013. High-throughput RNA sequencing of pseudomonas-infected Arabidopsis reveals hidden transcriptome complexity and novel splice variants. PLoS One 8:e74183.

Hu, J., Baker, A., Bartel, B., Linka, N., Mullen, R. T., Reumann, S., and Zolman, B. K. 2012. Plant peroxisomes: Biogenesis and function. Plant Cell 24:2279-2303.

Huerta-Cepas, J., Szklarczyk, D., Forslund, K., Cook, H., Heller, D., Walter, M. C., Rattei, T., Mende, D. R., Sunagawa, S., Kuhn, M., Jensen, L. J., von Mering, C., and Bork, P. 2016. eggNOG 4.5: A hierarchical orthology framework with improved functional annotations for eukaryotic, prokaryotic and viral sequences. Nucleic Acids Res. 44 (D1): D286-D293.

Ingvarsson, P. K. 2007. Gene expression and protein length influence codon usage and rates of sequence evolution in Populus tremula. Mol. Biol. Evol. 24:836-844.

Jones, J. D. G., and Dangl, J. L. 2006. The plant immune system. Nature 444:323-329.

Jones, P., Binns, D., Chang, H. Y., Fraser, M., Li, W., McAnulla, C., McWilliam, H., Maslen, J., Mitchell, A., Nuka, G., Pesseat, S., Quinn, A. F., Sangrador-Vegas, A., Scheremetjew, M., Yong, S. Y., Lopez, R., and Hunter, S. 2014. InterProScan 5: Genome-scale protein function classification. Bioinformatics 30:1236-1240.

Kabir, M. S., Ganley, R. J., and Bradshaw, R. E. 2015. The hemibiotrophic lifestyle of the fungal pine pathogen Dothistroma septosporum. For. Path. 45:190-202.

Kanzaki, H., Yoshida, K., Saitoh, H., Fujisaki, K., Hirabuchi, A., Alaux, L., Fournier, E., Tharreau, D., and Terauchi, R. 2012. Arms race coevolution of Magnaporthe oryzae AVR-Pik and rice Pik genes driven by their physical interactions. Plant J. 72:894-907.

Kim, D., Pertea, G., Trapnell, C., Pimentel, H., Kelley, R., and Salzberg, S. L. 2013. TopHat2: Accurate alignment of transcriptomes in the presence of insertions, deletions and gene fusions. Genome Biol. 14:R36.

Koenig, D., Hagmann, J., Li, R., Bemm, F., Slotte, T., Neuffer, B., Wright, S. I., and Weigel, D. 2019. Long-term balancing selection drives evolution of immunity genes in Capsella. eLife 8:e43606.

Kovalchuk, A., Zeng, Z., Ghimire, R. P., Kivimäenpää, M., Raffaello, T., Liu, M., Mukrimin, M., Kasanen, R., Sun, H., Julkunen-Tiitto, R., Holopainen, J. K., and Asiegbu, F. O. 2019. Dual RNA-seq analysis provides new insights into interactions between Norway spruce and necrotrophic pathogen Heterobasidion annosum s.l. BMC Plant Biol. 19:2.

Langfelder, P., and Horvath, S. 2008. WGCNA: An R package for weighted correlation network analysis. BMC Bioinformatics 9:559.

Larkin, M. A., Blackshields, G., Brown, N. P., Chenna, R., McGettigan, P. A., McWilliam, H., Valentin, F., Wallace, I. M., Wilm, A., Lopez, R., Thompson, J. D., Gibson, T. J., and Higgins, D. G. 2007. Clustal W and Clustal X version 2.0. Bioinformatics 23:2947-2948. 
Lechner, M., Findeiss, S., Steiner, L., Marz, M., Stadler, P. F., and Prohaska, S. J. 2011. Proteinortho: Detection of (co-)orthologs in large-scale analysis. BMC Bioinformatics 12:124.

Lenth, R. 2020. emmeans: Estimated Marginal Means, aka Least-Squares Means. R package version 1.5.0. CRAN-R.

Li, B., and Dewey, C. N. 2011. RSEM: Accurate transcript quantification from RNA-Seq data with or without a reference genome. BMC Bioinformatics 12:323.

Liu, J., Chen, X., Liang, X., Zhou, X., Yang, F., Liu, J., He, S. Y., and Guo, Z. 2016. Alternative splicing of rice WRKY62 and WRKY76 transcription factor genes in pathogen defense. Plant Physiol. 171:1427-1442.

Liu, J. J., and Ekramoddoullah, A. K. M. 2004. Characterization, expression and evolution of two novel subfamilies of Pinus monticola cDNAs encoding pathogenesis-related (PR)-10 proteins. Tree Physiol. 24: 1377-1385.

Liu, J. J., Sturrock, R. N., and Benton, R. 2013. Transcriptome analysis of Pinus monticola primary needles by RNA-seq provides novel insight into host resistance to Cronartium ribicola. BMC Genomics 14:884.

Macho, A. P., and Zipfel, C. 2014. Plant PRRs and the activation of innate immune signaling. Mol. Cell 54:263-272.

Mähler, N., Wang, J., Terebieniec, B. K., Ingvarsson, P. K., Street, N. R., and Hvidsten, T. R. 2017. Gene co-expression network connectivity is an important determinant of selective constraint. PLoS Genet. 13: e1006402.

Mann, H. B., and Whitney, D. R. 1947. On a test of whether one of two random variables is stochastically larger than the other. Ann. Math. Stat. 18:50-60.

Mbengue, M., Bourdais, G., Gervasi, F., Beck, M., Zhou, J., Spallek, T., Bartels, S., Boller, T., Ueda, T., Kuhn, H., and Robatzek, S. 2016. Clathrin-dependent endocytosis is required for immunity mediated by pattern recognition receptor kinases. Proc. Natl. Acad. Sci. U.S.A. 113: 11034-11039.

Mondragón-Palomino, M., Meyers, B. C., Michelmore, R. W., and Gaut, B. S. 2002. Patterns of positive selection in the complete NBS-LRR gene family of Arabidopsis thaliana. Genome Res. 12:1305-1315.

Mondragón-Palomino, M., Stam, R., John-Arputharaj, A., and Dresselhaus, T. 2017. Diversification of defensins and NLRs in Arabidopsis species by different evolutionary mechanisms. BMC Evol. Biol. 17:255.

Neale, D. B., Wegrzyn, J. L., Stevens, K. A., Zimin, A. V., Puiu, D., Crepeau, M. W., Cardeno, C., Koriabine, M., Holtz-Morris, A. E., Liechty, J. D., Martínez-García, P. J., Vasquez-Gross, H. A., Lin, B. Y., Zieve, J. J., Dougherty, W. M., Fuentes-Soriano, S., Wu, L. S., Gilbert, D., Marçais, G., Roberts, M., Holt, C., Yandell, M., Davis, J. M., Smith, K. E., Dean, J. F., Lorenz, W. W., Whetten, R. W., Sederoff, R., Wheeler, N., McGuire, P. E., Main, D., Loopstra, C. A., Mockaitis, K., deJong, P. J., Yorke, J. A., Salzberg, S. L., and Langley, C. H. 2014. Decoding the massive genome of loblolly pine using haploid DNA and novel assembly strategies. Genome Biol. 15:R59.

Olson-Manning, C. F. 2020. Elaboration of the corticosteroid synthesis pathway in primates through a multistep enzyme. Mol. Biol. Evol. 37: 2257-2267.

Parthasarathy, A., Cross, P. J., Dobson, R. C. J., Adams, L. E., Savka, M. A., and Hudson, A. O. 2018. A three-ring circus: Metabolism of the three proteogenic aromatic amino acids and their role in the health of plants and animals. Front. Mol. Biosci. 5:29.

R Core Team. 2018. R: A language and environment for statistical computing. R Foundation for Statistical Computing, Vienna. https: //www.R-project.org/.

Ramsay, H., Rieseberg, L. H., and Ritland, K. 2009. The correlation of evolutionary rate with pathway position in plant terpenoid biosynthesis. Mol. Biol. Evol. 26:1045-1053.
Ran, J. H., Shen, T. T., Wang, M. M., and Wang, X. Q. 2018 Phylogenomics resolves the deep phylogeny of seed plants and indicates partial convergent or homoplastic evolution between Gnetales and angiosperms. Proc. Biol. Sci. 285:20181012.

Robinson, M. D., McCarthy, D. J., and Smyth, G. K. 2010. edgeR: A Bioconductor package for differential expression analysis of digital gene expression data. Bioinformatics 26:139-140.

Sanabria, N. M., and Dubery, I. A. 2016. Alternative splicing of the receptor-like kinase $\mathrm{Nt-Sd-RLK}$ in tobacco cells responding to lipopolysaccharides: Suggestive of a role in pathogen surveillance and perception? FEBS Lett. 590:3628-3638.

Su, J., Yang, L., Zhu, Q., Wu, H., He, Y., Liu, Y., Xu, J., Jiang, D., and Zhang, S. 2018. Active photosynthetic inhibition mediated by MPK3/MPK6 is critical to effector-triggered immunity. PLoS Biol. 16: e2004122.

Sueldo, D. J., Shimels, M., Spiridon, L. N., Caldararu, O., Petrescu, A. J., Joosten, M. H. A. J., and Tameling, W. I. L. 2015. Random mutagenesis of the nucleotide-binding domain of NRC1 (NB-lrr required for hypersensitive response-associated cell death-1), a downstream signalling nucleotide-binding, leucine-rich repeat (NB-LRR) protein, identifies gain-of-function mutations in the nucleotide-binding pocket. New Phytol. 208:210-223.

Wang, W. M., Liu, P. Q., Xu, Y. J., and Xiao, S. 2016. Protein trafficking during plant innate immunity. J. Integr. Plant Biol. 58:284-298.

Warnes, G.R., Bolker, B., Bonebakker, L., Gentleman, R., Huber, W. H.A., Liaw, A., Lumley, T., Maechler, M., Magnusson, A., Moeller, S., Schwartz, M., and Venables, B. 2016. gplots: Various R programming tools for plotting data. R package version 3.0.1. ScienceOpen, Inc., Burlington, MA, U.S.A.

Welsh, C., Lewis, K., and Woods, A. 2009. The outbreak history of Dothistroma needle blight: An emerging forest disease in northwestern British Columbia, Canada. Can. J. For. Res. 39:2505-2519.

Wickham, H. 2011. The split-apply-combine strategy for data analysis. J. Stat. Softw. 40:1-29.

Wickham, H. 2016. ggplot2: Elegant graphics for data analysis. SpringerVerlag, New York.

Woods, A. J. 2003. Species diversity and forest health in northwest British Columbia. For. Chron. 79:892-897.

Woods, A. J., Coates, K. D., and Hamann, A. 2005. Is an unprecedented Dothistroma needle blight epidemic related to climate change? Bioscience 55:761-769.

Wu, T. D., and Watanabe, C. K. 2005. GMAP: A genomic mapping and alignment program for mRNA and EST sequences. Bioinformatics 21: 1859-1875.

Yang, S., Tang, F., and Zhu, H. 2014. Alternative splicing in plant immunity. Int. J. Mol. Sci. 15:10424-10445.

Yang, Z. 2007. PAML 4: Phylogenetic analysis by maximum likelihood. Mol. Biol. Evol. 24:1586-1591.

Ye, F., Albarouki, E., Lingam, B., Deising, H. B., and von Wirén, N. 2014. An adequate $\mathrm{Fe}$ nutritional status of maize suppresses infection and biotrophic growth of Colletotrichum graminicola. Physiol. Plant. 151: 280-292.

Yeaman, S., Hodgins, K. A., Suren, H., Nurkowski, K. A., Rieseberg, L. H., Holliday, J. A., and Aitken, S. N. 2014. Conservation and divergence of gene expression plasticity following c. 140 million years of evolution in lodgepole pine (Pinus contorta) and interior spruce (Picea glauca $\times$ Picea engelmannii). New Phytol. 203:578-591.

Yoshioka, H., Bouteau, F., and Kawano, T. 2008. Discovery of oxidative burst in the field of plant immunity: Looking back at the early pioneering works and towards the future development. Plant Signal. Behav. 3: 153-155. 